\title{
Attitudes About COVID-19 and Health (ATTACH): Online Survey and Mixed Methods Study
}

Anna M Hood ${ }^{1}$, BA, MA, PhD; Hanne Stotesbury ${ }^{1}$, MSc; Jennifer Murphy ${ }^{2}$, PhD; Melanie Kölbel ${ }^{1}$, MSc; April Slee ${ }^{3}$, MS; Charlie Springall ${ }^{4}$; Matthew Paradis ${ }^{4}, \mathrm{PhD}$; Nadia Saraí Corral-Frías ${ }^{5}, \mathrm{PhD}$; Azalea Reyes-Aguilar ${ }^{6,7}, \mathrm{PhD}$; Alfredo B Cuellar Barboza ${ }^{8}$, MD; Amy E Noser ${ }^{9}$, PhD; Stacey Gomes ${ }^{9,10}$, MS; Monica Mitchell ${ }^{9,11}$, PhD; Sharon M Watkins $^{12}$, BA; Melinda Butsch Kovacic ${ }^{11}$, MPH, PhD; Fenella J Kirkham ${ }^{1^{*}}$, MD; Lori E Crosby ${ }^{9,13^{*}}$, PsyD

${ }_{1}^{1}$ Developmental Neurosciences Unit and Biomedical Research Centre, University College London Great Ormond Street Institute of Child Health, London, United Kingdom

${ }^{2}$ Department of Psychology, Royal Holloway University of London, London, United Kingdom

${ }^{3}$ Axio Research LLC, Seattle, WA, United States

${ }^{4}$ AirMyOpinion Ltd, Weybridge, United Kingdom

${ }^{5}$ Department of Psychology, Universidad de Sonora, Hermosillo, Sonora, Mexico

${ }^{6}$ Department of Psychobiology, Facultad de Psicología, Universidad Nacional Autónoma de México, Ciudad de México, Mexico

${ }^{7}$ Department of Neuroscience, Facultad de Psicología, Universidad Nacional Autónoma de México, Ciudad de México, Mexico

${ }^{8}$ Department of Psychiatry, Universidad Autonoma de Nuevo Leon, Monterrey, Mexico

${ }^{9}$ Behavioral Medicine and Clinical Psychology, Cincinnati Children's Hospital Medical Center, Cincinnati, OH, United States

${ }^{10}$ College of Criminal Justice, Education and Human Services, University of Cincinnati College of Medicine, Cincinnati, OH, United States

${ }^{11}$ Department of Pediatrics, University of Cincinnati College of Medicine, Cincinnati, OH, United States

${ }^{12}$ Cincinnati-Hamilton County Community Action Agency, Cincinnati, OH, United States

${ }^{13}$ James M Anderson Center for Health Systems Excellence, Cincinnati Children's Hospital Medical Center, Cincinnati, OH, United States

* these authors contributed equally

\section{Corresponding Author:}

Anna M Hood, BA, MA, PhD

Developmental Neurosciences Unit and Biomedical Research Centre

University College London Great Ormond Street Institute of Child Health

30 Guilford Street

London, WC1N 1EH

United Kingdom

Phone: 4402079052744

Email: a.hood@ucl.ac.uk

\section{Abstract}

Background: Behavioral mitigation strategies to slow the spread of COVID-19 have resulted in sweeping lifestyle changes, with short- and long-term psychological, well-being, and quality of life implications. The Attitudes About COVID-19 and Health (ATTACH) study focuses on understanding attitudes and beliefs while considering the impact on mental and physical health and the influence of broader demographic and geographic factors on attitudes, beliefs, and mental health burden.

Objective: In this assessment of our first wave of data collection, we provide baseline cohort description of the ATTACH study participants in the United Kingdom, the United States, and Mexico. Additionally, we assess responses to daily poll questions related to COVID-19 and conduct a cross-sectional analysis of baseline assessments collected in the UK between June 26 and October 31, 2020.

Methods: The ATTACH study uses smartphone app technology and online survey data collection. Participants completed poll questions related to COVID-19 2 times daily and a monthly survey assessing mental health, social isolation, physical health, and quality of life. Poll question responses were graphed using 95\% Clopper-Pearson (exact) tests with 95\% CIs. Pearson correlations, hierarchical linear regression analyses, and generalized linear models assessed relationships, predictors of self-reported outcomes, and group differences, respectively. 
Results: By October 31, 2020, 1405, 80, and 90 participants had consented to participate in the UK, United States, and Mexico, respectively. Descriptive data for the UK daily poll questions indicated that participants generally followed social distancing measures, but worry and negative impacts on families increased as the pandemic progressed. Although participants generally reported feeling that the reasons for current measures had been made clear, there was low trust that the government was doing everything in its power to meet public needs. In the UK, 1282 participants also completed a monthly survey (94.99\% [1326/1396] White, 72.22\% [1014/1404] female, and 20.12\% [277/1377] key or essential workers); 18.88\% (242/1282) of UK participants reported a preexisting mental health disorder, $31.36 \%(402 / 1282)$ reported a preexisting chronic medical illness, and $35.11 \%$ $(493 / 1404)$ were aged over $65 ; 57.72 \%$ (740/1282) of participants reported being more sedentary since the pandemic began, and $41.89 \%(537 / 1282)$ reported reduced access to medical care. Those with poorer mental health outcomes lived in more deprived neighborhoods, in larger households $\left(P_{\mathrm{s}}<.05\right)$, had more preexisting mental health disorders and medical conditions, and were younger than 65 years (all $P_{\mathrm{s}}<.001$ ).

Conclusions: Communities who have been exposed to additional harm during the COVID-19 pandemic were experiencing worse mental outcomes. Factors including having a medical condition, or living in a deprived neighborhood or larger household were associated with heightened risk. Future longitudinal studies should investigate the link between COVID-19 exposure, mental health, and sociodemographic and residential characteristics.

(JMIR Ment Health 2021;8(10):e29963) doi: 10.2196/29963

\section{KEYWORDS}

COVID-19; mental health; international; mitigation strategies; deprivation

\section{Introduction}

\section{Background}

The COVID-19 (SARS-CoV-2 virus) pandemic has placed an overwhelming burden on health systems and public health authorities to respond with effective interventions, policies, and messages [1]. Efforts to develop vaccines began quickly, with the first human clinical trial of a COVID-19 vaccine commencing on March 3, 2020, in the United States [2]. In the UK, the COVID-19 vaccine was authorized for clinical use on December 2, 2020 [3], with Mexico following soon afterward on December 11, 2020 [4]. Even with these pharmacological measures, behavioral mitigation strategies (eg, physical distancing, handwashing, face masks) [5] remain critical to slow the spread of COVID-19 [6]. However, the effectiveness of these behavioral strategies is dependent on adherence to policies and guidelines and on a person's ability to perceive risks associated with the virus and adapt accordingly [7].

As the mitigation guidelines change over time and differ between countries and regions, there are many areas of uncertainty, including financial and health concerns, employment, and housing, along with fear about the future and social isolation. These sources of uncertainty may impact coping and increase the risk of developing mental health problems, with implications for quality of life in both the short and long term [8,9]. Families have had to juggle home-schooling children with working remotely or being unable to work at all [10]. Evidence from previous viral disease outbreaks indicates that when the number of stressors is high, there can be a negative effect on mental health, particularly for high-risk persons (eg, survivors and frontline health care workers) [11-15]. Currently, individuals are reporting widespread concerns about the effect of social distancing on well-being. There is evidence of increased anxiety, depression, and stress, along with reports of concern about the practical implications of the pandemic response, including for personal finances $[9,16]$.

Social and medical factors play a significant role in COVID-19 exposure and influence the impact on mental health. It has quickly become apparent that these social and medical consequences of COVID-19 do not affect all people equally. Older adults, people with medical conditions (eg, asthma, sickle cell disease), and those facing long-standing societal inequities (ie, Black, Latinx, Indigenous, Asian, and traveler communities) face a disproportionate burden [17]. A report from Public Health England indicated that socioeconomic disadvantage, population density, and household composition may increase the likelihood not only of COVID-19 illness and severe disease [18] but also of poorer mental health outcomes [19,20]. Individuals' concerns about their mental health outcomes will likely result in additional pressure on referral systems. Known barriers to accessing mental health interventions may also increase during the pandemic, such as distance, work commitments, and caring responsibilities.

\section{Goal of This Study}

The Attitudes About COVID-19 and Health (ATTACH) study aims to understand attitudes and beliefs about the COVID-19 pandemic while considering the impact on mental and physical health, along with the influence of demographic and geographic factors. We examine how the pandemic and behavioral mitigation strategies influence attitudes and beliefs, which in turn are predicted to affect mental and physical health (eg, anxiety, social isolation) and therefore influence overall quality of life (see Figure 1 for the theoretical model). Specifically, to assess the impact of COVID-19-related measures (eg, isolation, physical distancing), our study: (1) tracks attitudes and behaviors daily as the pandemic evolves, and (2) longitudinally monitors mental and physical health symptoms using established measures that are reliable and sensitive to change. 
Figure 1. Theoretical model.

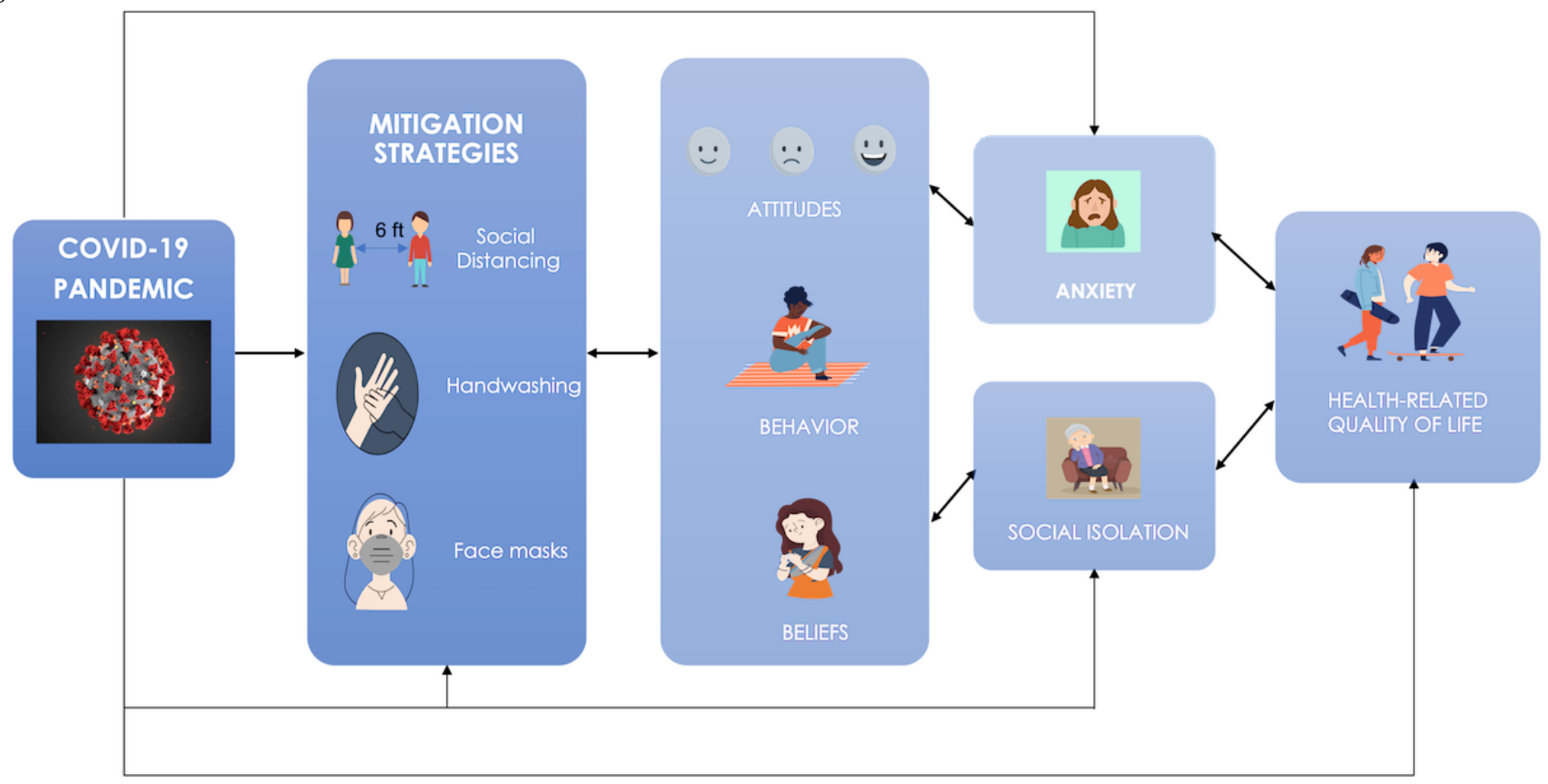

The ATTACH study uses a smartphone app and online survey data collection. Our goals necessitate oversampling those communities that have been exposed to additional harm during the COVID-19 pandemic to guide the development of effective, and ideally, more person-centered interventions. Data encompass a sample from the United Kingdom (a high-resource country). We also include data from 2 smaller-scale studies from the United States (another high-resource country) and Mexico (a low-resource country). We chose these countries for inclusion because, before the pandemic, the Global Health Security Index ranked the United States and the UK as the first and second most prepared countries to manage a pandemic, but by June 2020, they were the first and second in excess deaths related to COVID-19 [21]. Mexico has Latin America's second highest death toll and had 50\% excess deaths when data collection began [22]. As Mexico is a primarily Spanish-speaking country with a similarly challenging COVID-19 response as the United States and the UK, the comparison could help better understand attitudes, behaviors, and mental health during the COVID-19 pandemic. Although behavioral mitigation strategies changed regularly during the study period, all 3 countries used lockdowns (eg, shelter in place), social distancing, and relied on individual compliance with the new rules. Additionally, some form of mask mandate had been introduced in all 3 countries, hospitality venues had been closed or required outdoor dining, and stores limited the number of individuals allowed inside [23-25]. However, COVID-19 vaccines had not been released in any of these countries at the time of data collection.

Data collection for ATTACH is ongoing, and longitudinal aims and specific hypotheses have been preregistered [26]. This paper primarily focuses on a cross-sectional analysis of baseline assessments collected in the UK between June 26 and October 31,2020 . It also considers longitudinal changes in UK daily poll responses through the same period. Descriptive analyses for data from the United States and Mexico are also reported, but we did not conduct statistical analyses. During the first wave, the sample sizes in those countries were less than 100 participants.

\section{Aims}

The objectives of this study were to (1) describe the baseline characteristics of participants in the ATTACH study in the UK, United States, and Mexico; and (2) describe changes in daily UK poll responses over time in relation to specific policy interventions (eg, mask mandates) and the pandemic's trajectory (eg, a 7-day rolling average of COVID-19 cases).

\section{Hypotheses}

We hypothesized that residential population density, socioeconomic deprivation, and household composition will predict self-reported outcomes (ie, anxiety and depressive symptoms, social isolation, physical health, quality of life) in our UK sample; and there will be baseline differences in our UK sample in self-reported outcomes between (1) participants with and without mental health disorders, (2) participants with and without medical conditions, and (3) participants under and over the age of 65 .

\section{Methods}

\section{Study Design}

ATTACH is a prospective cohort study conducted nationwide during the COVID-19 pandemic with arms in the UK, the United States, and Mexico. Our research team developed the study between March and April 2020. Data collection began on June 26, 2020, in the UK, on July 27, 2020, in the United States, and on October 10, 2020, in Mexico. In the UK, the ATTACH study partnered with Air My Opinion (AMO), a smartphone app that enables organizations to gather longitudinal poll data to interpret trends in attitudes and beliefs. 


\section{Population}

The ATTACH study purposely targets individuals with increased susceptibility to adverse health outcomes for recruitment, focusing on 3 priority groups: (1) those with a self-reported mental health disorder, (2) those with a self-reported chronic medical condition, and (3) those over 65 years of age. Participants were at least 16 years of age ( 18 years in the United States and Mexico), could read in English (UK; does not have to be their first language), Spanish (Mexico), or English or Spanish (United States). Participants had to reside in the country where the study was being completed and have access to a smartphone (UK) and the internet (UK, the United States, and Mexico). Participants provided informed electronic consent before completing daily poll questions and monthly surveys. The ATTACH study received ethical approval from the University College London (UCL) Research Ethics Committee (18177/001), the Cincinnati Children's Hospital Medical Center Institutional Review Board (No. 2020-0465), and the Universidad de Sonora Ethics Committee (CEI-UNISON 010/2020). The study is reported in accordance with the STrengthening the Reporting of OBservational studies in Epidemiology (STROBE) [27] and the Checklist for Reporting Results of Internet E-Surveys (CHERRIES) guidelines [28].

\section{Materials}

\section{Air My Opinion App (UK Data Only)}

The AMO app was customized for the ATTACH study through an iterative design process between the research team and app developer. Before the study launched, the research team appraised a mock-up design, highlighted their satisfaction and dissatisfaction with the design and format, and provided feedback and suggestions for improvement. The AMO app uses the flutter framework, has embedded encryption, and is General Data Protection Regulation (GDPR) compliant. Participants could freely install the app on an internet-enabled smartphone (Google Play or Apple App Store) running Android or iOS operating systems. Responses to daily poll questions were collected via an SMS text message service-center voting platform. Some participants $(n=344)$ had difficulty sending their first SMS text message (ie, changed the wording, did not realize it had not been sent), which included their registration data (ie, postcode). As such, the app development team made changes so that registration data were incorporated within the app instead of being included in the first SMS text message.

If a participant's phone plan is the traditional pay-as-you-go, they pay for each SMS text message, but if they have a monthly plan or pay-as-you-go bundle, there is no additional cost. Each phone number is associated with a unique 1-way encrypted participant key (eg, 1::747d6f41-2f7a-47fd-a2a0-0cf41b8ca9f2 $::$ i2::1::484::), which feeds directly into a secure response firewall-protected database (Figure 2). According to GDPR, age range, sex, postcode, ethnic minority status (yes/no prefer not to say), and parent and chronic medical condition group status were stored in a separate secure firewall-protected database. Data protection registration has been obtained for this study (UCL Data Protection Registration Number: Z6364106/2020/04/110). The data are minimized at the first opportunity, with new keys assigned and the original keys stored separately from the rest of the data on the UCL shared drive.

Figure 2. Smartphone survey polling system. AMO: Air My Opinion.

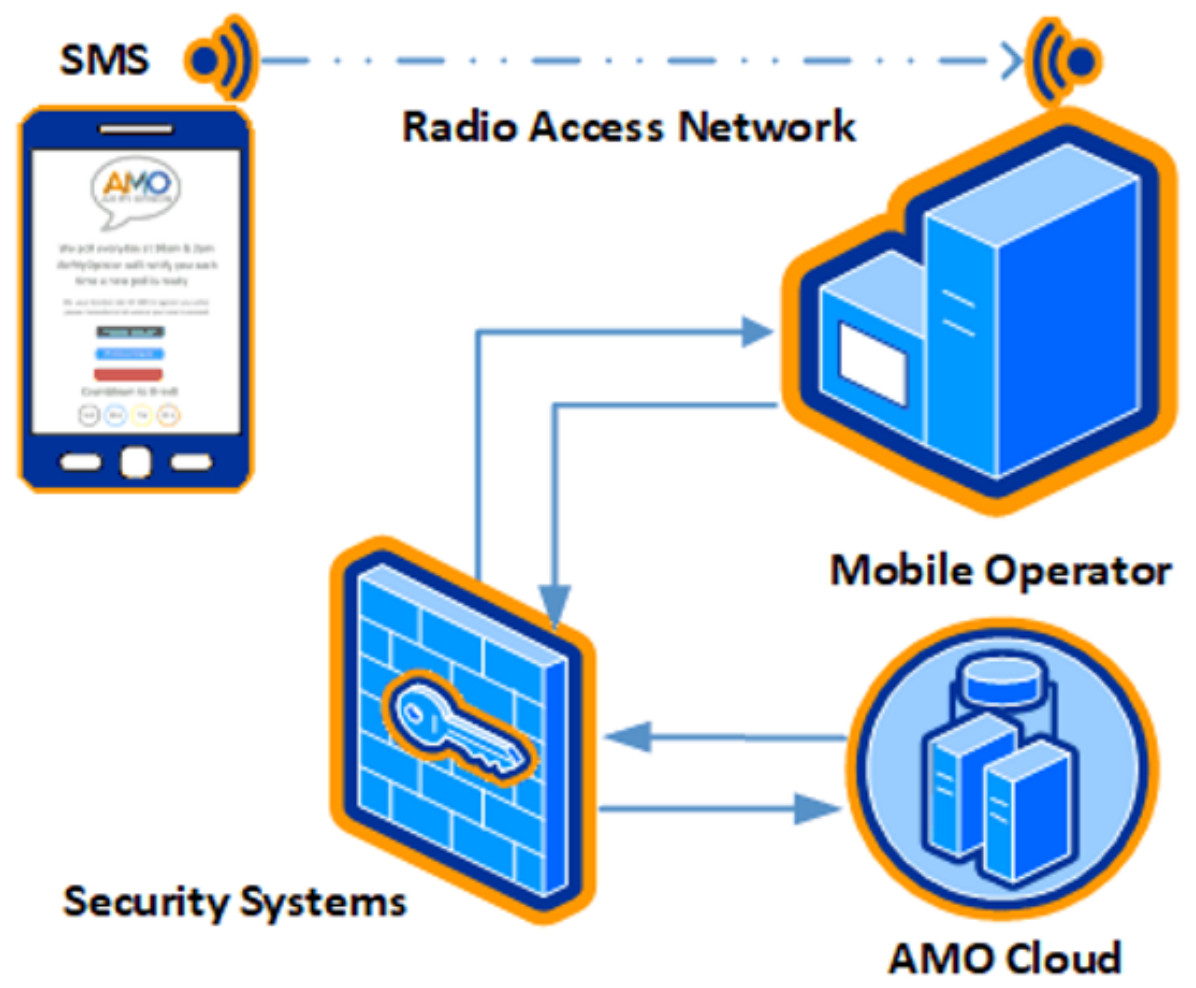




\section{Poll Questions (UK Data Only)}

In March and April 2020, the research team conducted a literature review and held several virtual video conference meetings to develop daily poll questions using prior expertise, survey knowledge, group discussion, and reliable sources of COVID-19 information (eg, World Health Organization [WHO]). Given the fast-moving nature of the COVID-19 pandemic, validation or pilot testing of questions externally was not possible. Poll questions track attitudes, beliefs, and behaviors related to the COVID-19 pandemic and fit into broad categories related to health and well-being, personal concerns, worry or hope, compliance or rationale, government trust, and habits. All questions have 3 Likert response options (eg, yes, somewhat, not at all). There are currently 60 poll questions. New questions are added on a flexible schedule to capture changes during the pandemic while maintaining the original questions for longitudinal assessment (see Multimedia Appendix 1 for a complete list of poll questions). Most questions are repeated every 2 weeks. In this study, 6 questions were focused on descriptive analyses (see below). These questions were chosen as they were asked continuously from the beginning of the study, represent a question from each category, and were chosen before any analyses were conducted.

- In the past week, have you followed social distancing measures?

- In the past week, have you felt that COVID-19 has had a negative impact on your family?

- In the past week, how worried have you been about the ongoing COVID-19 pandemic?

- In the past week, have you felt that the reasons for the current pandemic measures have been made clear?

- In the past week, have you trusted the government to do everything in their power to ensure that the basic needs of the public are met?

- In the past week, have you spent more time than usual using social media (eg, Facebook, WhatsApp, Instagram)?

\section{Monthly Survey}

Baseline sociodemographic characteristics included age, sex, relationship status, educational level, first language, household composition, and caregiver status. For race and ethnicity, participants could choose from categories (based on census data from each country) or self-identify using a free response. Mental health disorders and medical conditions were identified from free response. Mental health disorders were classified based on the Diagnostic and Statistical Manual of Mental Disorders, 5th Edition [29] categories. To capture changes as the COVID-19 pandemic progresses, participants were asked to provide their employment and keyworker status, effects on household income, sources of and trust in COVID-19-related information, and political status on a 100 -point scale (" $0=$ left" and " $100=$ right") at baseline and at months 7 and 12 .

Measures included in the study are validated, nonvalidated (developed rapidly during the COVID-19 pandemic), and those designed by our research team. Internal consistency (ie, Cronbach $\alpha$ ) for this study and the assessment schedule are reported in Multimedia Appendices 2 and 3. When possible, short forms of measures were used to reduce participant burden.
Measures included for analyses in this study were the Patient-Reported Outcomes Measurement Information System (PROMIS) Anxiety-Adult Short Form [30], 9-item Patient Health Questionnaire (PHQ-9) [31], 10-item University of California Los Angeles Loneliness Scale (UCLA-10) [32], PROMIS Global Health [30], the PROMIS Meaning and Purpose-Short Form [30], and the Epidemic-Pandemic Impact Inventory (Physical Health questions) [33] (Multimedia Appendix 4). PROMIS measures were available in Spanish; for the other measures, a study team member (NC-F) completed the translation.

\section{Residential Risk Factors (UK Data Only)}

\section{Overview}

Geographic region, socioeconomic disadvantage, and household composition may influence an individual's ability to follow COVID-19-related guidelines and restrictions [18]. In our study, 2 measures captured these factors: deprivation and population density. Participants provided the first 5 characters of their UK postcode (ie, postcode sector) on the AMO smartphone app. In 2016, there were 12,381 postcode sectors in the UK. Postcode sectors vary in terms of the number of dwellings but typically range between 200 and 5000 [34].

\section{Socioeconomic Deprivation}

The index of multiple deprivation (IMD; 2017-2020) is an official postcode-based measure of relative deprivation in England [35], Wales [36], Scotland [37], and Northern Ireland [38] and is available as open-source government data. The IMD defines deprivation to encompass income, employment, education, health, crime, barriers to housing and services, and living environment. All neighborhoods are ranked on a relative rather than absolute scale according to their deprivation level relative to other areas. All zones are grouped into 5 bands (quintiles), each containing $20 \%$ of the zone, with " $1=$ most deprived, 5=least deprived." In this study, each participants' postcode sector was assessed to determine the level of deprivation. IMD quintile scores are combined from all UK countries.

\section{Residential Population Density}

Population density estimates for England and Wales [39], Scotland [40], and Northern Ireland [41] are produced for each country using the cohort component method and cover the "usually resident population" from 2011 Census data. In this study, each participants' postcode sector was assessed to determine the population density (ie, number of usual residents per hectare), and population density was combined from all UK countries.

\section{Household Composition}

Participants responded to the question, "How many people (adults and children) live in your household?" The 5 response options were " 1 " through "5 or more."

\section{Procedures}

Recruitment strategies for all countries are described in Multimedia Appendix 5. Participants downloaded the smartphone app to complete consent in the UK and then 
provided their demographics (in case a participant chose not to complete monthly surveys) and postcode. Participants received push notifications on their smartphones to complete daily 1-minute polls 2 times each day at 10 am and $2 \mathrm{pm}$. Participants could answer both questions at the same time, but each question was removed after 24 hours. Once the participant completed the daily poll questions, they could then click on an embedded link (with a unique access code) in the app to complete their monthly survey via Research Electronic Data Capture tools (REDCap) hosted at UCL (see Figure 3 for a schematic) [42,43].
Figure 3. Schematic of an Attitudes About COVID-19 and Health study notification and
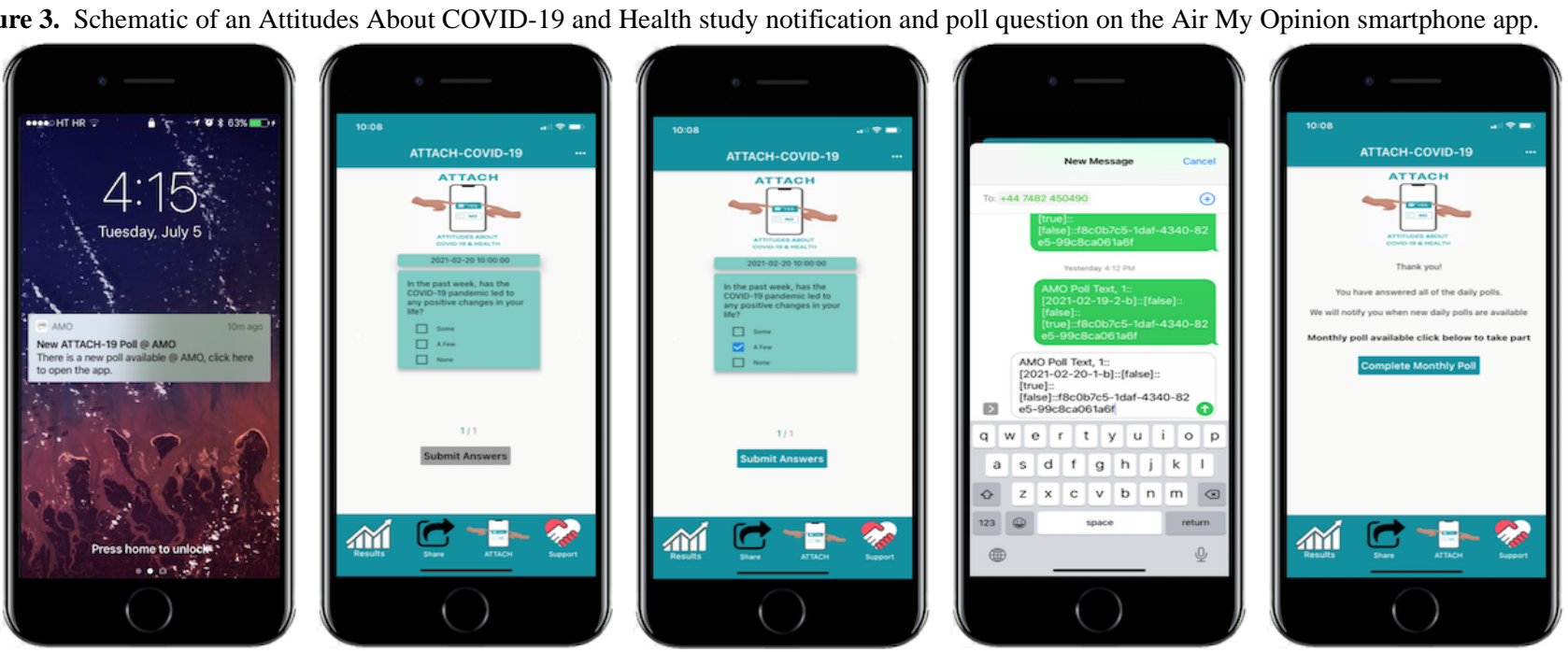

If responses to survey questions indicated that participants had severe depression or experienced high levels of stigma due to their medical condition, a pop-up message provided mental health resources along with the study email address, which was monitored regularly by a clinical psychologist $(\mathrm{AH})$ to provide additional resources or referrals. After the survey, participants were redirected to the study webpages (located on the UCL Child Health Institute website), which contain links to mental health (eg, Mind), COVID-19 (eg, government), and authoritative medical information (eg, National Health Service [NHS]). Participants could see the results of daily poll questions (as pie charts) by clicking on a link in the app or via the study Twitter account.

In the United States, participants completed poll questions and monthly surveys using REDCap, and in Mexico, participants completed monthly surveys using Qualtrics (Qualtrics International Inc) with open survey links. Participants in the UK and United States who completed the monthly survey were entered into a monthly prize draw (UK $£ 10$ [US \$13.75]/US $\$ 10$ Amazon card). In Mexico, most participants did not receive any compensation. A subset of the sample (ie, undergraduate students) had the opportunity to receive culture credits (obtained through research studies or going to concerts or workshops) for their participation.

\section{Statistical Analysis}

Analyses were conducted using R version 4.0.3 [44] and SAS version 9.4 [45]. Descriptive statistics summarized demographic and clinical characteristics. The PROMIS [30] Anxiety, Physical Health, and the Meaning and Purpose scales were scored using the online HealthMeasures scoring service [46] that utilizes information from each item to calculate a T-score (mean 50 [SD 10]). For the PHQ-9 and UCLA-10 scales, raw scores were calculated in line with published norms. Mean imputation was used when a participant completed at least $80 \%$ of items (ie, $8 / 10$ for the UCLA-10 or $8 / 9$ for the PHQ-9) [47,48]. The frequency of somewhat and yes poll question responses from July 15,2020 , to October 15,2020 , was graphed based on the timing of response using 95\% Clopper-Pearson (exact) tests with $95 \%$ CIs, alongside the 7-day average counts of daily COVID-19 cases (per 100 persons) and deaths. Pearson correlations examined the relationship between household composition and self-reported outcomes. Hierarchical linear regression analyses assessed whether residential socioeconomic deprivation and population density independently predicted self-reported outcomes after controlling for age and sex.

Generalized linear models were used to produce adjusted least-square mean scores and differences to compare groups (participants with and without mental health and medical conditions, those under and over 65 years). Analyses controlled for demographic factors (ie, age, sex, level of residential socioeconomic deprivation) and comorbidities (ie, mental health and medical condition). All analyses were conducted using pairwise deletion, as variables generally contained less than $1 \%$ of missing data. Adjusted $P$ values were based on the model $t$-statistics. Semipartial $\eta^{2}$ was used as a measure of effect size to describe the proportion of total variation accounted for by the effect being tested. Statistical significance was determined at an $\alpha$ level of $P<.05$ ( 2 tailed).

\section{Data Exclusion}

The smartphone app and online survey data were examined for duplicates by matching unique app identifiers and participant numbers. Through this process, it was determined that 15 participants had downloaded the app more than once. Duplicate data were excluded before analyses.

\section{Power}

The ATTACH study was powered to detect longitudinal effects and not baseline group differences [26], so power calculations were not performed for these largely descriptive first-wave baseline assessments. However, for our longitudinal analyses 
with 3 subgroups, 5 covariates, 5 or more repeated measures at 0.80 power, an error probability of 0.05 , and an effect size of 0.3 , the sample size required for between-participants analyses is 153 and 50 for within-participants analyses.

\section{Data Sharing}

Data will be shared upon reasonable request and with permission according to the ATTACH Group data release policy.

\section{Results}

\section{UK Preliminary Analyses}

By October 31, 2020, 1405 individuals had downloaded the smartphone app and consented to participate in the UK ATTACH study. As of October 31, 2020, the study link that takes participants to the study recruitment page had been clicked on 5068 times, with Facebook and Twitter being the most common referrers. No participants reached out via email or social media to indicate that they had a mental health concern.

A total of $123 / 1405$ participants $(8.75 \%)$ answered poll questions on at least one occasion but did not complete the monthly survey. Sensitivity analyses indicated that participants who did and did not go on to complete the survey were similar in age $(P=.24)$, sex $(P=.62)$, level of deprivation $(P=.83)$, and UK country of residence $(P=.74)$. However, those who did not complete a monthly survey were significantly more likely to identify as non-White $(P<.001)$ and were from a more populated geographic region $(P=.02)$ than those who did. Analyses assessed whether there were differences between participants who did and did not $(n=344)$ send their first SMS text message correctly. They did not differ in terms of identified race $(P=.54)$, but they were significantly older $(P<.001)$ and more likely to be female $(P=.02)$.

\section{UK Poll Questions}

About $62.63 \%(880 / 1405)$ of participants answered each poll question separately at 10 am and $2 \mathrm{pm}$, with the fastest response at 8 seconds and the slowest response at 23 hours and 58 minutes. The average time to answer 1 question was 2 hours and 17 minutes, with $11.88 \%$ (167/1405) of participants answering within 10 minutes. Longitudinal data from 6 poll questions indicated that participants had generally followed social distancing measures, although there was variability across time (responses varied between 50\% and 99\%). Regarding whether the COVID-19 pandemic had a negative impact on the family and whether participants were worried about the pandemic, both increased over time. Over $80 \%$ of participants responded "somewhat or yes" as the pandemic progressed and as the 7-day rolling average of cases and deaths increased. Although participants generally reported feeling that the reasons for current measures had been made clear $(70 \%-85 \%$ across the study period), there was much less trust that the government was doing everything in their power to meet public needs, with less variability in responses over time $(25 \%-50 \%$ across the study period). Increased social media use remained consistent, with $30 \%-40 \%$ of participants reporting spending more time than usual (Figures 4-9).

Figure 4. Graphs represent United Kingdom longitudinal daily poll responses for COVID-19-related question in the category of health from July 15 , 2020, to October 15, 2020. Error bars represent 95\% CIs. Participant responses "somewhat" and "yes" are grouped together for analyses.

\section{In the past week, have you followed social distancing measures?}

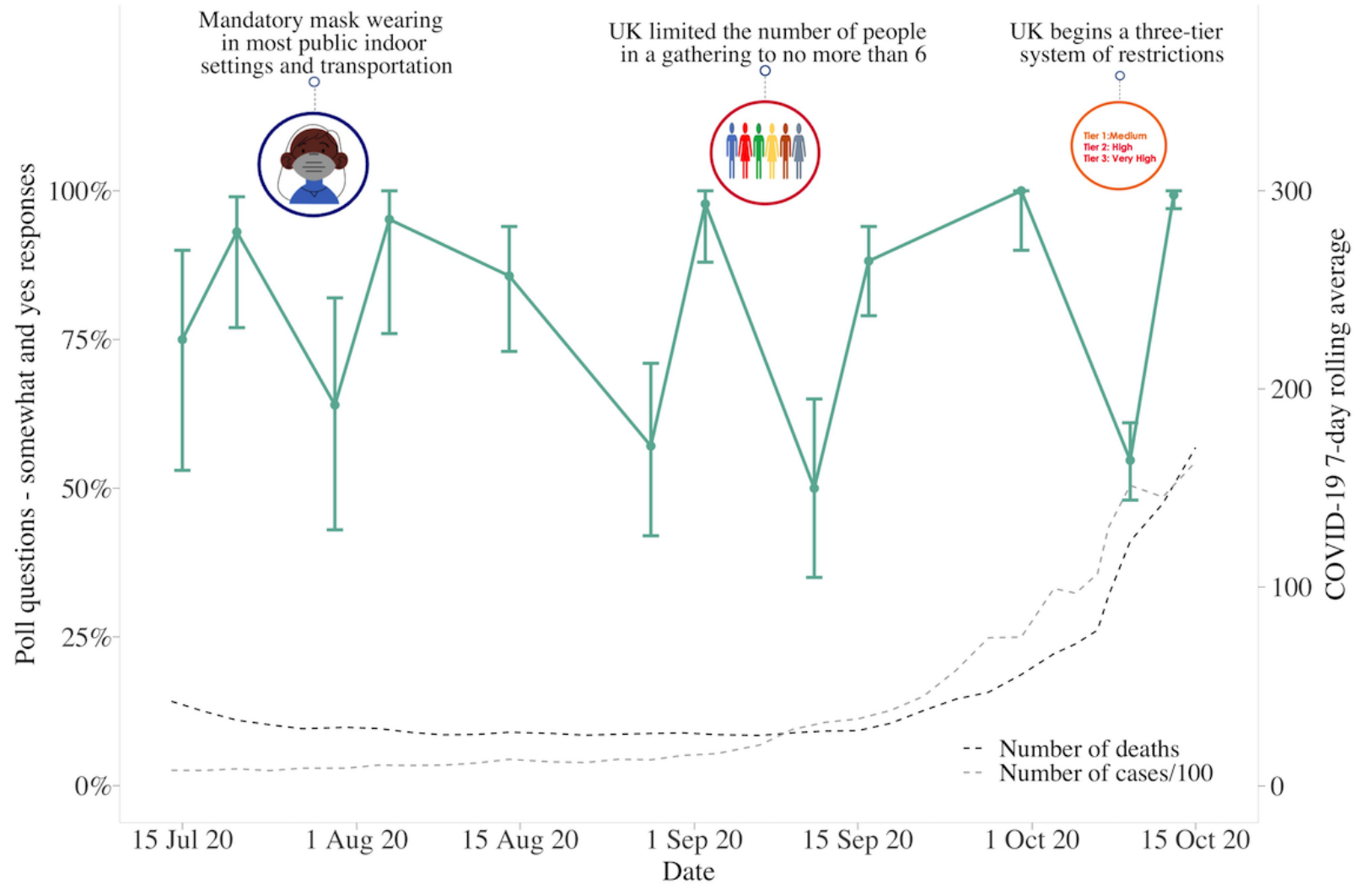


Figure 5. Graphs represent United Kingdom longitudinal daily poll responses for COVID-19-related question in the category of personal concerns from July 15, 2020, to October 15, 2020. Error bars represent 95\% CIs. Participant responses "somewhat" and "yes" are grouped together for analyses.

In the past week have you felt that COVID-19 has had a negative impact on your family?

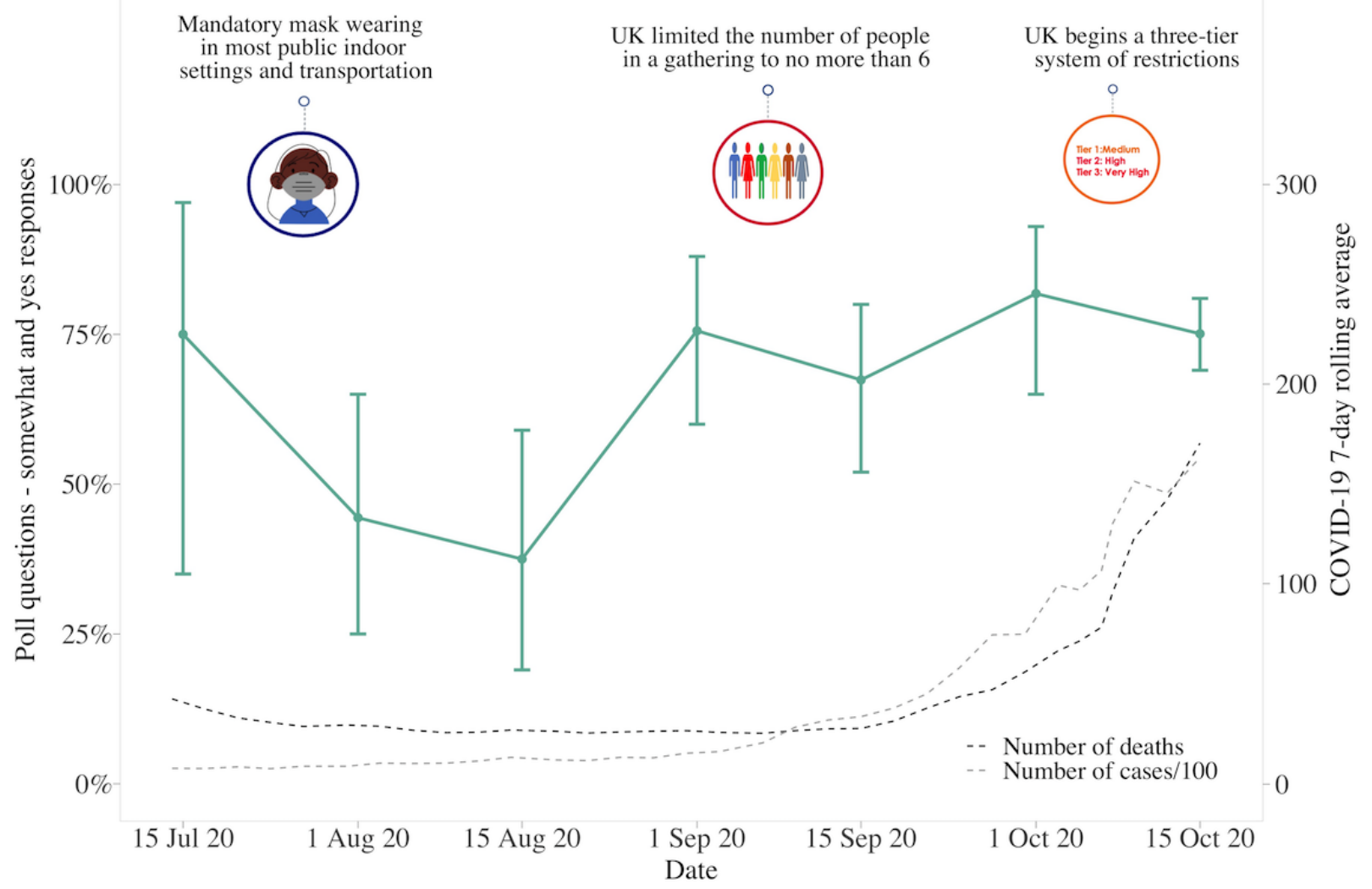

Figure 6. Graphs represent United Kingdom longitudinal daily poll responses for COVID-19-related question in the category of worry or hope from July 15, 2020, to October 15, 2020. Error bars represent 95\% CIs. Participant responses "somewhat" and "yes" are grouped together for analyses.

In the past week, how worried have you been about the ongoing COVID-19 pandemic?

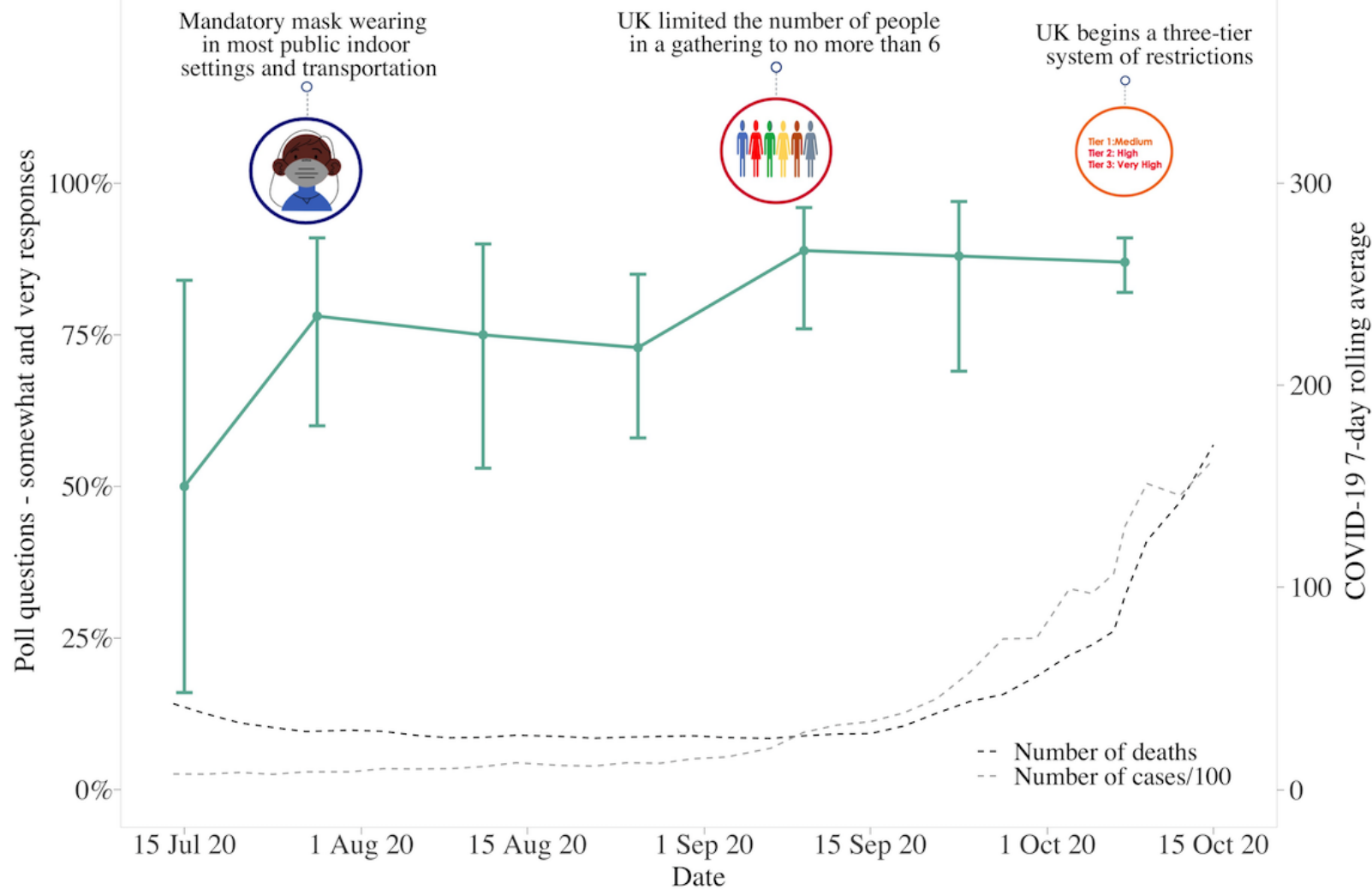


Figure 7. Graphs represent United Kingdom longitudinal daily poll responses for COVID-19-related question in the category of compliance or rationale from July 15, 2020, to October 15, 2020. Error bars represent 95\% CIs. Participant responses "somewhat" and "yes" are grouped together for analyses.

In the past week, have you felt that the reasons for the current pandemic measures have been made clear?

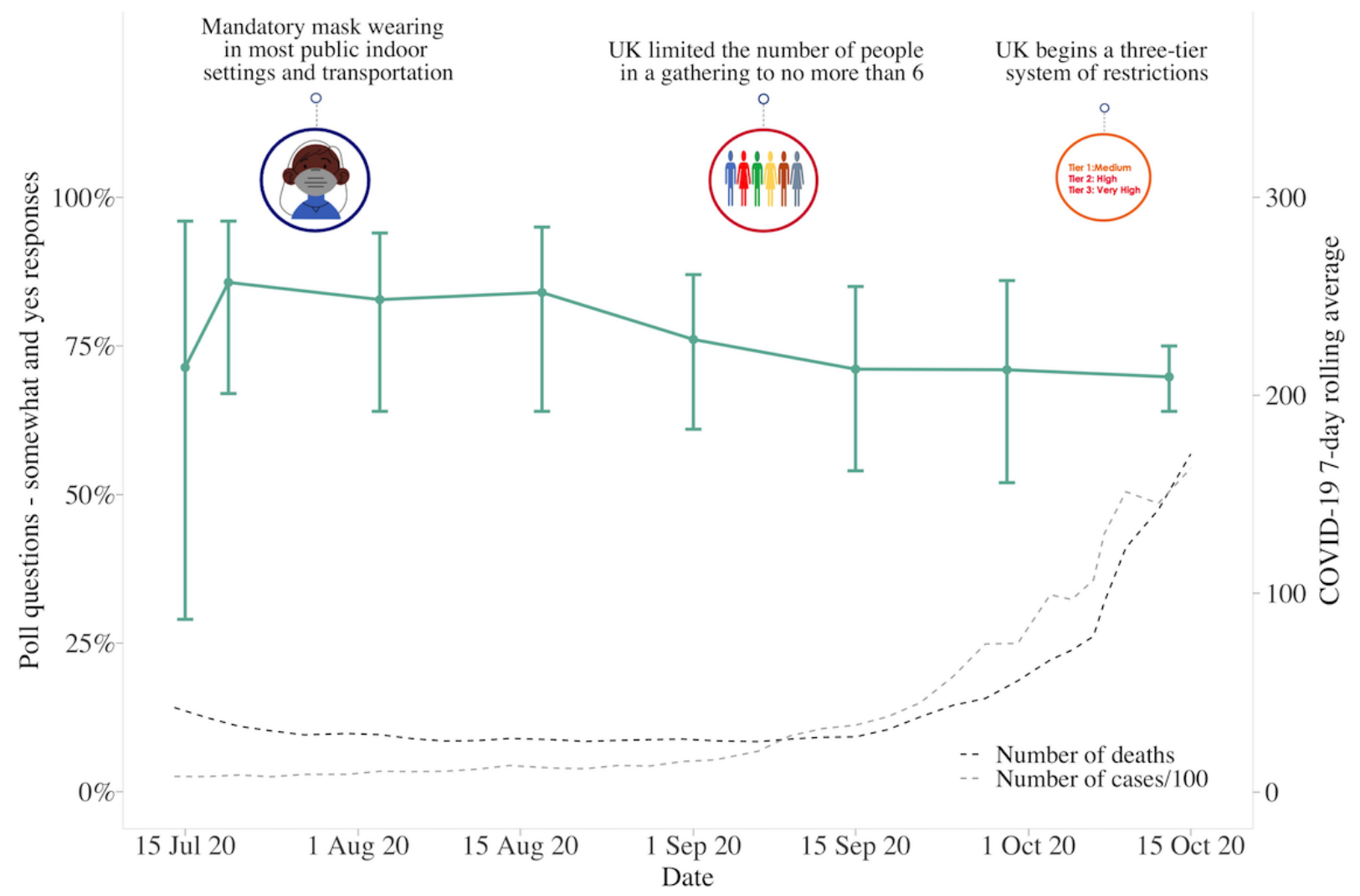

Figure 8. Graphs represent United Kingdom longitudinal daily poll responses for COVID-19-related question in the category of government trust from July 15, 2020, to October 15, 2020. Error bars represent 95\% CIs. Participant responses "somewhat" and "yes" are grouped together for analyses.

\section{In the past week, have you trusted the government to do everything in their power to ensure that the basic needs of the public are met?}

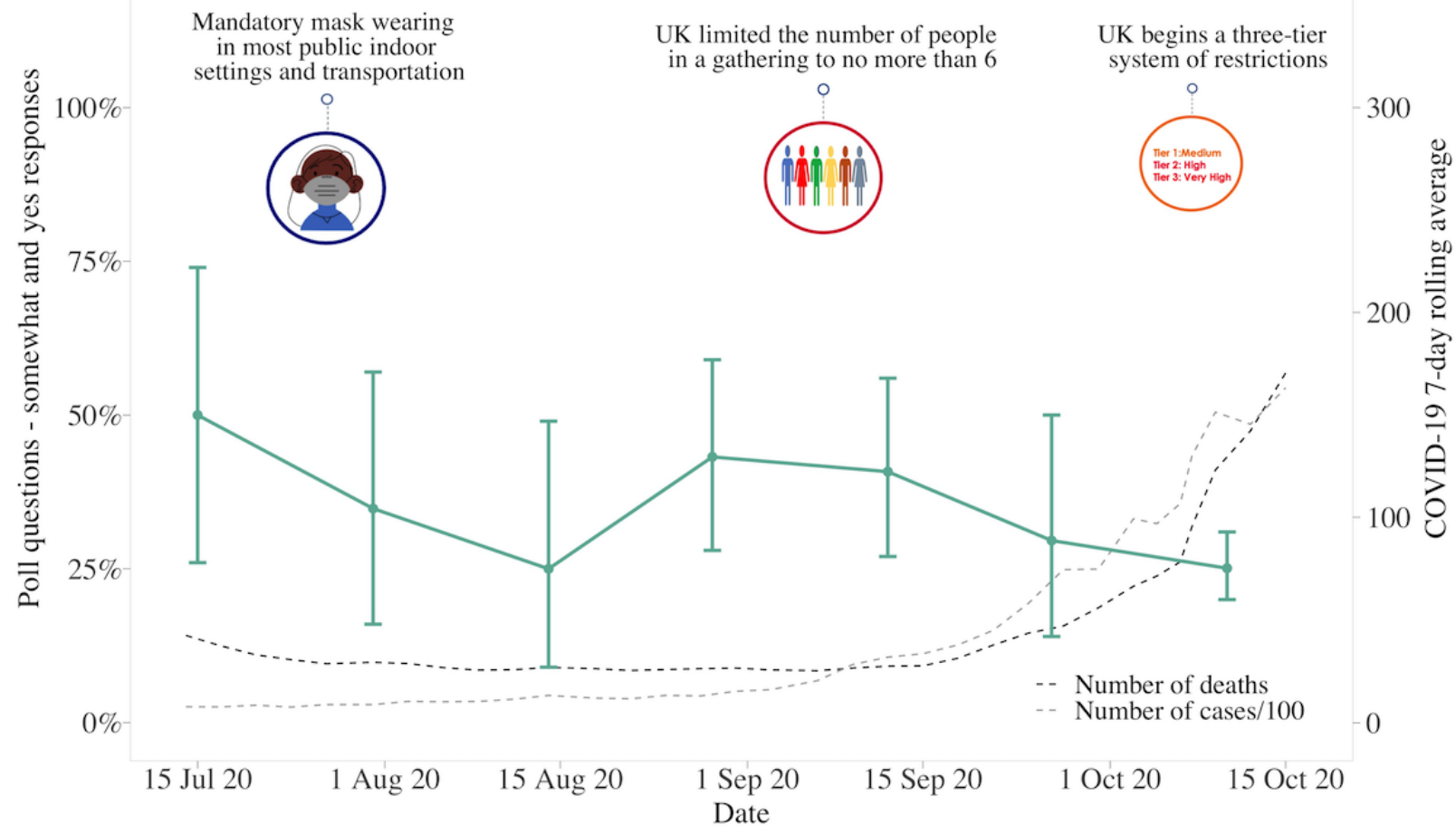


Figure 9. Graphs represent United Kingdom longitudinal daily poll responses for COVID-19-related question in the category of habits from July 15, 2020, to October 15, 2020. Error bars represent 95\% CIs. Participant responses "somewhat" and "yes" are grouped together for analyses.

\section{In the past week, have you spent more time than usual using social media (eg, Facebook, WhatsApp, Instagram)?}

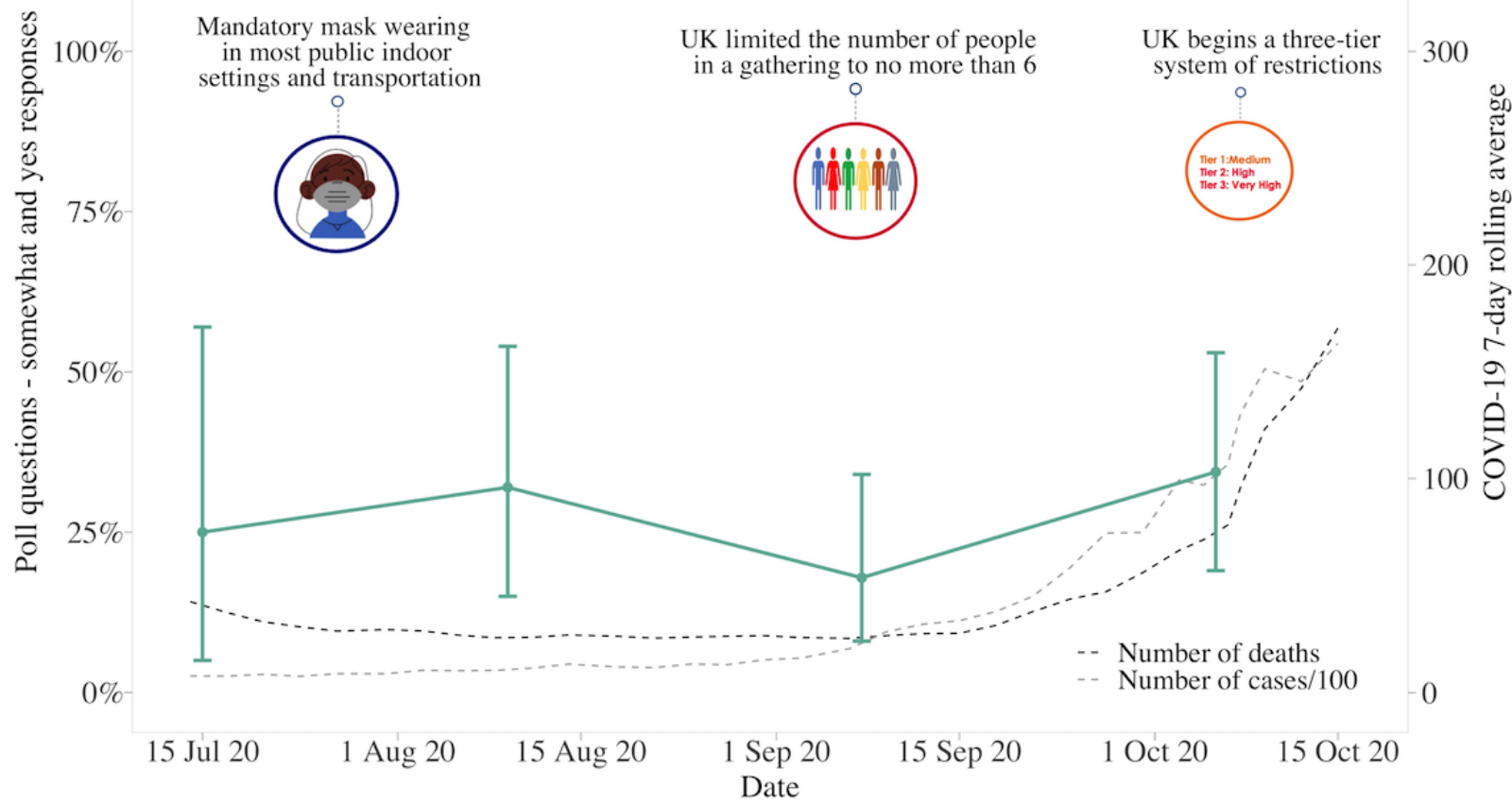

\section{UK Monthly Survey}

\section{Descriptive Data}

Participants at baseline had a mean age of 57 years, with the majority identifying as White (1326/1396, 94.99\%), female (1014/1404, 72.22\%), married (765/1282, 59.67\%), speaking English as a first language (1231/1282, 96.02\%), and educated to the college/university level or higher (996/1282, 77.69\%). A total of 540/1262 participants $(42.78 \%)$ were retired, and about one-fifth $(277 / 1377,20.12 \%)$ were key or essential workers. Most lived in a 2-person household (681/1282, 53.12\%), and a minority were parents of children under 16 years $(139 / 1282$, $10.84 \%)$. Less than a quarter $(300 / 1259,23.83 \%)$ reported that their income had been affected by the COVID-19 pandemic, and when reporting where they see themselves on the political spectrum, scores ranged from 0 to 100 (mean 42.3 [SD 22.2]; Multimedia Appendix 6).

A subgroup of participants reported preexisting mental health disorders $(242 / 1282,18.88 \%)$, with depression and anxiety disorders being the most commonly reported. Just over one-third $(402 / 1282,31.36 \%)$ reported a preexisting chronic medical illness, with asthma, Type 1 and 2 diabetes, and arthritis being the most commonly reported (Multimedia Appendix 7). Some participants also had comorbid (ie, more than 1) mental health disorders $(94 / 1282,7.33 \%)$ or chronic medical illnesses (71/1282, 5.54\%). Additionally, some participants had at least one mental health disorder and at least one chronic medical condition (100/1282, 7.80\%; Multimedia Appendix 8). Scores on self-reported outcome measures indicated that just under one-third of the sample $(352 / 1244,28.30 \%)$ was experiencing moderate-to-severe anxiety symptoms, while just under one-fifth $(233 / 1217,19.15 \%)$ was experiencing moderate-to-severe depressive symptoms. Most of the sample (985/1232, 79.95\%) reported feeling some loneliness or social isolation, while 248/1208 (20.53\%) participants reported poor-to-fair physical health, and 476/1206 (39.47\%) reported poor-to-fair quality of life (Multimedia Appendix 8).

\section{Impact of the COVID-19 Pandemic}

Participants reported how the COVID-19 pandemic had changed their lives and impacted their household members. Generally, fewer participants reported physical health changes, although many had received less routine or preventative medical care. At least one-third of the sample reported being less physically active and eating less healthy foods. In fact, $57.72 \%$ (740/1282) of participants reported being more sedentary since the pandemic began (Table 1). 
Table 1. COVID-19 pandemic-related changes for participants and people in their home at baseline in the UK ATTACH study from June 26 to October 31,2020 .

\begin{tabular}{lll}
\hline COVID-19 pandemic-related changes & Participant, $\%^{\mathrm{a}}$ & Person in home, $\%^{\mathrm{a}}$ \\
\hline Spent more time sitting down or being sedentary & 57.7 & 30.8 \\
Got less medical care than usual (eg, routine or preventive care appointments) & 41.7 & 23.0 \\
Less physical activity or exercise & 40.7 & 23.7 \\
Overeating or eating more unhealthy foods (eg, junk food) & 31.9 & 16.8 \\
Increase in health problems not related to this disease & 21.1 & 12.3 \\
Important medical procedure cancelled (eg, surgery) & 6.9 & 5.4 \\
Elderly or disabled family member not in the home/unable to get the help they need & 5.5 & 6.9 \\
Unable to access medical care for a serious condition (eg, dialysis, chemotherapy) & 2.3 & 1.3 \\
\hline
\end{tabular}

${ }_{n} \mathrm{n}$ is not reported because it is different for each question as not all participants answered each question. The $\mathrm{n}$ ranged from 1280 to 1282 participant responses for each question.

\section{Residential Risk Factors}

Pearson correlations demonstrated that residential socioeconomic deprivation was significantly related to increased population density $(r=-0.24 ; \quad P<.001)$ and household composition ( $r=0.07 ; P=.04)$. Higher household composition (ie, more people residing in the home) was, however, related to less residential population density $(r=-0.06 ; P=.09)$, although this result did not reach significance.

\section{Socioeconomic Deprivation}

Younger age, female sex, and living in a more deprived neighborhood (ie, quintile 1 vs quintiles 2 through 5) were predictive of reporting more anxiety symptoms, $F_{8,880}=23.12$, $r^{2}=0.13(95 \%$ CI $0.09-0.17 ; P<.001)$. For our second analysis, younger age and living in a more deprived neighborhood (ie, quintile 1 vs quintiles 2 through 5), but not sex, were predictive of reporting more depressive symptoms, $F_{6,862}=25.87, r^{2}=0.15$ (95\% CI 0.11-0.19; $P<.001)$. For our third and fourth analyses, age $(P=.40$ and .17 , respectively) and sex $(P=.22$ and .34 , respectively) were not significant predictors, but living in a more deprived neighborhood (ie, quintile 1) compared with living in a less deprived neighborhood (quintiles 2 through 5) was predictive of reporting worse physical health, $F_{6,860}=2.88$, $r^{2}=0.13(95 \%$ CI $0.00-0.04 ; P<.001)$ and more social isolation (only the least deprived quintile), $F_{6,872}=11.60, r^{2}=0.08(95 \%$ CI $0.04-0.10 ; P<.001)$. For our fifth analysis on quality of life, the overall model was significant, $F_{6,860}=6.19, r^{2}=0.03(95 \%$ CI $0.01-0.06 ; P<.001)$. However, only female sex $(P=.03)$ was a significant predictor of worse quality of life. Overall, these analyses indicated that living in the most deprived neighborhoods (quintile=1) predicted worse mental health, increased social isolation, and poorer physical health.

\section{Residential Population Density}

Hierarchical linear regression analyses assessed whether residential population density significantly predicted self-reported outcomes after controlling for the age and sex of participants. We found that age $(P \mathrm{~s}<.01)$ but not sex $(P \mathrm{~s}>.05)$ was a significant predictor in all 5 regression models, indicating that younger participants were more likely to live in neighborhoods with higher population density. With regard to self-reported outcomes, the severity of anxiety and depressive symptoms and reporting more social isolation and poorer physical health were not predictive of living in a more populated neighborhood $(P \mathrm{~s}>.05)$. By contrast, participants who reported poor quality of life were more likely to live in a more populated area than those who reported excellent quality of life, $\mathrm{t}_{861}=2.21$, $\beta=-.31(95 \% \mathrm{CI}-0.58$ to $-0.03 ; P=.03)$.

\section{Household Composition}

Pearson correlations found small, but significant relationships between higher household composition and more anxiety $(r=0.07 ; P=.01)$ and depressive symptoms $(r=0.07 ; P=.01)$. Higher household composition was, however, related to less social isolation $(r=-0.06 ; P=.07)$, although this result did not reach significance. Household composition was not related to physical health or quality of life $\left(P_{\mathrm{S}}>.05\right)$.

\section{Differences Between Groups}

We found that participants with mental health disorders reported significantly more anxiety and depressive symptoms, more social isolation, worse physical health, and poorer quality of life than those without a mental health disorder (all $P_{\mathrm{S}}<.001$ ) after controlling for age, sex, level of residential socioeconomic deprivation, and comorbid medical conditions (Table 2). Tables 2-4 focus on specific group contrasts; however, the covariates in each model are identical. Thus, the following model-level goodness-of-fit statistics apply to each model: Anxiety (PROMIS 7 T-score), $\mathrm{R}^{2}=0.224$; Depression (PHQ-9 total score), $\mathrm{R}^{2}=0.298$; Social Isolation (UCLA 10-item total), $\mathrm{R}^{2}=0.114$; Social Isolation (UCLA 3-item total), $\mathrm{R}^{2}=0.111$; Physical Health (PROMIS T-score), $\mathrm{R}^{2}=0.204$; and quality of life (PROMIS T-score), $\mathrm{R}^{2}=0.091$.

After controlling for age, sex, level of residential socioeconomic deprivation, and comorbid mental health disorders, we found that participants with medical conditions reported significantly more anxiety $(P=.003)$ and depressive symptoms $(P=.002)$, and worse physical health (all $P<.001)$ than those without a medical 
condition. Social isolation and quality of life were similar for both groups (Ps>.05; Table 3).

After controlling for sex, level of residential socioeconomic deprivation, and comorbid mental health and medical conditions, we found that contrary to hypotheses, participants under 65 years of age reported significantly more anxiety and depressive symptoms and more social isolation than those over 65 years of age (all $\left.P_{\mathrm{s}}<.001\right)$. They also reported slightly better quality of life $(P=.05)$, although both groups were in the average range according to the measure classifications. Participants over and under 65 years reported similar physical health $(P=.88$; Table 4).

Table 2. Differences in self-reported outcomes for those with and without mental health disorders.

\begin{tabular}{|c|c|c|c|c|c|c|c|c|}
\hline Self-reported outcomes & $\mathrm{n}$ & $\begin{array}{l}\text { No mental health disorder, } \\
\operatorname{LSM}^{\mathrm{a}}(\mathrm{SE})\end{array}$ & $\mathrm{n}$ & $\begin{array}{l}\text { Mental health disorder, } \\
\text { LSM (SE) }\end{array}$ & $\begin{array}{l}\text { LSM difference } \\
\text { (CI) }\end{array}$ & $t(d f)$ & $\eta^{2}$ & $P$ \\
\hline $\begin{array}{l}\text { Anxiety: PROMIS } 7 a^{c} \mathrm{~T}- \\
\text { score }\end{array}$ & 987 & $52.2(0.4)$ & 227 & $60.6(0.7)$ & $-8.4(-9.8$ to -6.9$)$ & $-11.3(866)$ & 0.9 & $<.001$ \\
\hline $\begin{array}{l}\text { Depression: } \mathrm{PHQ}-9^{\mathrm{d}} \text { total } \\
\text { score }\end{array}$ & 970 & $4.0(0.2)$ & 218 & $10.4(0.4)$ & $-6.4(-7.2$ to -5.6$)$ & $-15.5(849)$ & 0.6 & $<.001$ \\
\hline $\begin{array}{l}\text { Social Isolation: } \mathrm{UCLA}^{\mathrm{e}} \\
\text { 10-item total }\end{array}$ & 978 & $19.4(0.3)$ & 224 & $23.4(0.5)$ & $-4.1(-5.1$ to -3.1$)$ & $-8.1(858)$ & 0.9 & $<.001$ \\
\hline $\begin{array}{l}\text { Social Isolation: UCLA } \\
\text { 3-item total }\end{array}$ & 978 & $6.3(0.1)$ & 224 & $7.6(0.2)$ & $-1.3(-1.7$ to -1.0$)$ & $-7.1(858)$ & 0.9 & $<.001$ \\
\hline $\begin{array}{l}\text { Physical Health: } \\
\text { PROMIS T-score }\end{array}$ & 963 & $51.7(0.4)$ & 217 & $46.3(0.7)$ & $5.4(4.0$ to 6.8$)$ & $7.4(847)$ & 1.0 & $<.001$ \\
\hline QOL $^{f}$ : PROMIS T-score & 961 & $48.9(0.5)$ & 217 & $41.6(0.9)$ & $7.4(5.6$ to 9.2$)$ & $8.0(847)$ & 1.0 & $<.001$ \\
\hline
\end{tabular}

${ }^{a}$ LSM: least square mean.

${ }^{\mathrm{b}} \mathrm{SE}$ : standard error.

${ }^{\mathrm{c}}$ PROMIS: Patient-Reported Outcomes Measurement Information System.

${ }^{\mathrm{d}} \mathrm{PHQ}$-9: 9-item Patient Health Questionnaire.

${ }^{\mathrm{e} U C L A}$ : UCLA Loneliness Scale.

${ }^{\mathrm{f}} \mathrm{QOL}$ : quality of life.

Table 3. Differences in self-reported outcomes for those with and without medical conditions.

\begin{tabular}{|c|c|c|c|c|c|c|c|c|}
\hline Self-reported outcomes & $\mathrm{n}$ & $\begin{array}{l}\text { No medical condition, } \\
\operatorname{LSM}^{\mathrm{a}}(\mathrm{SE})\end{array}$ & $\mathrm{n}$ & $\begin{array}{l}\text { Medical condition, } \\
\mathrm{LSM}_{(\mathrm{SE})}{ }^{\mathrm{b}}\end{array}$ & $\begin{array}{l}\text { LSM difference } \\
\text { (CI) }\end{array}$ & $t(d f)$ & $\eta^{2}$ & $P$ \\
\hline $\begin{array}{l}\text { Anxiety: PROMIS } 7 \mathrm{a}^{\mathrm{c}} \\
\text { T-score }\end{array}$ & 848 & $56.2(2.0)$ & 396 & $58.1(2.1)$ & $-1.9(-3.1$ to -0.6$)$ & $-2.9(866)$ & 1.0 & .003 \\
\hline $\begin{array}{l}\text { Depression: PHQ-9 } \\
\text { Total score }\end{array}$ & 831 & $8.2(1.1)$ & 386 & $9.3(1.1)$ & $-1.1(-1.8$ to -0.4$)$ & $-3.1(849)$ & 0.5 & .002 \\
\hline $\begin{array}{l}\text { Social Isolation: } \\
\text { UCLA }^{\text {e }} 10 \text {-item total }\end{array}$ & 842 & $21.1(1.4)$ & 390 & $21.6(1.4)$ & $-0.5(-1.3$ to 0.4$)$ & $-1.5(858)$ & 0.9 & .25 \\
\hline $\begin{array}{l}\text { Social Isolation: UCLA } \\
\text { 3-item total }\end{array}$ & 842 & $6.7(0.5)$ & 390 & $6.9(0.5)$ & -0.3 ( -0.6 to 0.02$)$ & $-1.9(858)$ & 0.9 & .06 \\
\hline $\begin{array}{l}\text { Physical Health: } \\
\text { PROMIS T-score }\end{array}$ & 823 & $45.8(2.0)$ & 385 & $52.6(2.0)$ & $6.9(5.6$ to 8.1$)$ & $11.1(847)$ & 1.0 & $<.001$ \\
\hline $\begin{array}{l}\text { QOL }{ }^{f} \text { : PROMIS T- } \\
\text { score }\end{array}$ & 821 & $43.2(2.5)$ & 385 & $42.6(2.5)$ & 0.7 (-0.9 to 2.2$)$ & $0.8(847)$ & 1.0 & .40 \\
\hline
\end{tabular}

${ }^{a}$ LSM: least square mean.

${ }^{\mathrm{b}} \mathrm{SE}$ : standard error.

${ }^{c}$ PROMIS: Patient-Reported Outcomes Measurement Information System.

${ }^{\mathrm{d}}$ PHQ-9: 9-item Patient Health Questionnaire.

${ }^{\mathrm{e}}$ UCLA: UCLA Loneliness Scale.

${ }^{f}$ QOL: quality of life. 
Table 4. Differences in self-reported outcomes for those over and under 65 years.

\begin{tabular}{|c|c|c|c|c|c|c|c|c|}
\hline Self-reported outcomes & $\mathrm{n}$ & $\begin{array}{l}\text { Under } 65 \text { years, LSM } \\
(\mathrm{SE})^{\mathrm{a}}\end{array}$ & $\mathrm{n}$ & $\begin{array}{l}\text { Over } 65 \text { years, LSM } \\
(\mathrm{SE})^{\mathrm{b}}\end{array}$ & $\begin{array}{l}\text { LSM difference } \\
\text { (CI) }\end{array}$ & $t(d f)$ & $\eta^{2}$ & $P$ \\
\hline $\begin{array}{l}\text { Anxiety: PROMIS } 7 \mathrm{a}^{\mathrm{c}} \mathrm{T}- \\
\text { score }\end{array}$ & 800 & $58.6(2.0)$ & 444 & $55.7(2.1)$ & 3.0 (1.7 to 4.2$)$ & $4.7(866)$ & 1.0 & $<.001$ \\
\hline $\begin{array}{l}\text { Depression: PHQ-9 }{ }^{\mathrm{d}} \text { Total } \\
\text { score }\end{array}$ & 827 & $9.8(1.1)$ & 454 & $7.8(1.2)$ & $2.0(1.3$ to 2.7$)$ & $5.7(849)$ & 0.5 & $<.001$ \\
\hline $\begin{array}{l}\text { Social Isolation: } \mathrm{UCLA}^{\mathrm{e}} 10- \\
\text { item total }\end{array}$ & 827 & $22.2(1.4)$ & 454 & $20.5(1.4)$ & $1.7(0.8$ to 2.5$)$ & $3.9(858)$ & 0.9 & $<.001$ \\
\hline $\begin{array}{l}\text { Social Isolation: UCLA 3- } \\
\text { item total }\end{array}$ & 827 & $7.1(0.5)$ & 454 & $6.5(0.5)$ & $0.6(0.3$ to 1.0$)$ & $4.1(858)$ & 0.9 & $<.001$ \\
\hline $\begin{array}{l}\text { Physical health: PROMIS T- } \\
\text { score }\end{array}$ & 827 & $49.2(2.0)$ & 454 & $49.3(1.9)$ & $0.1(-1.1$ to 1.3$)$ & $0.2(847)$ & 1.0 & .88 \\
\hline QOL $^{f}$ : PROMIS T-score & 827 & $42.1(2.5)$ & 454 & $43.6(2.5)$ & $-1.5(-3.0$ to -0.1$)$ & $-1.98(847)$ & 1.0 & .05 \\
\hline
\end{tabular}

${ }^{\mathrm{a}} \mathrm{LSM}$ : least square mean.

${ }^{\mathrm{b}_{\mathrm{SE}}} \mathrm{SE}$ standard error.

${ }^{\mathrm{c}}$ PROMIS: Patient-Reported Outcomes Measurement Information System.

${ }^{\mathrm{d}}$ PHQ-9: 9-item Patient Health Questionnaire.

eUCLA: UCLA Loneliness Scale.

${ }^{\mathrm{f}}$ QOL: quality of life.

\section{The United States}

At baseline, participants in the smaller-scale US ATTACH study $(\mathrm{n}=90)$ were younger than the UK sample (mean 47.1 [SD 13.1]), more likely to identify as Black/African American $(45 / 90,50 \%)$, be employed $(69 / 90,77 \%)$, be key or essential workers $(40 / 90,44 \%)$, be parents of children under 16 years $(34 / 90,38 \%)$, and be educated at the college/university level or higher $(85 / 90,94 \%)$. Participants in the United States were less likely than those living in the UK to report that they were married (42/90, 47\%), have a mental health disorder (12/90, $13 \%$ ), and when reporting where they see themselves on the political spectrum; scores ranged from 0 to 100 (mean 34.0 [SD 21.6]). The 2 samples were similar in that the majority were female (68/90, 76\%), English speakers (78/90, 87\%), reported having a medical condition $(26 / 90,29 \%)$, most lived in a 2-person household (33/90, 37\%), and less than a quarter (22/90, $24 \%$ ) reported that their income had been affected by the COVID-19 pandemic (Multimedia Appendix 9).

\section{Mexico}

During the first wave of baseline assessments, the Mexico ATTACH study $(n=80)$ had been collecting data for less than 1 month. Participants were more likely than the UK sample to be younger than 40 years $(71 / 80,89 \%)$, identify as mixed/multiple ethnic groups (40/80, 50\%), be single (48/90, $53 \%$ ), be unemployed or employed without income (ie, furloughed; 42/80,53\%), to live in a 3-person household or larger $(58 / 80,73 \%)$, and be a caregiver to a child under 16 years $(17 / 80,21 \%)$. Similar to the UK sample, most participants were female $(59 / 80,74 \%)$, were educated to the college/university level or higher $(48 / 80,60 \%)$, had a mental health disorder $(22 / 80,28 \%)$, and when reporting where they see themselves on the political spectrum; scores ranged from 0 to 100 (mean 46.9 [SD 25.3]; Multimedia Appendix 10).

\section{Discussion}

\section{Principal Findings}

This paper offers a description of longitudinal trends in attitudes and behaviors related to the COVID-19 pandemic. Additionally, we report descriptive data from 2 smaller-scale mirror studies conducted in the United States and Mexico for comparison. Descriptive data for the UK daily poll questions indicated that participants generally followed social distancing measures, but worry and negative impact on families increased as the pandemic progressed. Our cross-sectional baseline assessment in a UK adult population indicated that those with poorer mental health outcomes lived in more deprived neighborhoods, in larger households, had more preexisting mental health disorders and medical conditions, and were younger than 65 years.

In terms of the UK pandemic trajectory, cases and deaths were relatively stable for most of this period, with more rapid increases observed only in the final month. UK longitudinal smartphone data from 6 poll questions indicated that as the pandemic progressed and the 7-day rolling average of cases and deaths began to increase rapidly, participants became more worried about the pandemic with a corresponding negative impact on their families. Although most people felt that information about the COVID-19 pandemic had been conveyed clearly, their trust in the government response was much lower. Nevertheless, participants reported generally following social distancing measures (responses varied between 50\% and 99\%), and $30 \%-40 \%$ of participants also reported spending more time than usual using social media, even though the average age of our UK sample was nearly 60 years.

Cross-sectional data from our first-wave baseline assessments in the UK yielded several important findings. Participants with preexisting mental health disorders reported worse outcomes 
across all mental health and psychosocial indicators. Unsurprisingly, those with preexisting mental disorders reported more symptomatology. However, those with medical conditions and younger participants (age < 65) also had increased psychological symptomatology. Specifically, 139/396 (35.1\%) and 50/386 (13.0\%) of participants with chronic medical conditions reported currently experiencing moderate-to-severe anxiety and depressive symptoms, respectively. Similarly, $285 / 827(34.5 \%)$ and $93 / 827(11.2 \%)$ of younger participants (<65 years) reported currently experiencing moderate-to-severe anxiety and depressive symptoms, respectively.

These data parallel other UK cohort studies conducted during the COVID-19 pandemic, as we found that depressive and anxiety symptomology was higher in our UK sample relative to epidemiological data collected before the COVID-19 pandemic [49-52]. We had hypothesized that older adults (>65 years) in our sample would experience worse mental health outcomes than younger participants because older people are at higher risk for worse COVID-19-related outcomes. However, after controlling for demographic factors and comorbid mental health and medical conditions, this was not the case. Instead, our data suggest chronic medical conditions are a greater risk factor than older age for poor mental health outcomes. The relationships identified between deprivation, population density, and household composition suggest that they may be surrogates for poorer housing, overcrowding, or the need to use public transportation, which increase the risk of COVID exposure.

Consistent with other online surveys assessing mental health outcomes, women were over-represented in our study sample [51]. Although this overrepresentation limits some of our conclusions, women are experiencing a disproportionate economic and employment burden related to COVID-19, along with mothers having increased childcare responsibilities [53]. These factors could have long-term deleterious effects on mental health. As our study moves into longitudinal analysis, we can determine how mental health symptoms are related to attitudes and behaviors associated with COVID-19 and whether robust, rather than uncertain, public health measures ameliorate mental health difficulties [54]. Future interventions will need to be tailored to individual and community needs while tackling entrenched preexisting mental health inequities.

Other notable findings from this study were the relationship between mental health, psychosocial outcomes, and potential risk factors, although they likely existed before the COVID-19 pandemic. Data revealed that those with poor quality of life were more likely than those with excellent quality of life to live in more populated neighborhoods. Further, higher household composition was related to more anxiety and depressive symptoms, but appeared protective with regard to social isolation. Most prominently, living in the most socioeconomically deprived neighborhoods (quintile=1) was predictive of worse outcomes for all indicators, except quality of life. These results are concerning because they indicate the potential for an exacerbation of preexisting inequities, particularly if future interventions are not tailored with a consideration of these factors. Evidence shows that those who live in the most deprived neighborhoods are hospitalized more frequently for COVID-19 infections [55]. Our results indicate that the impact of neighborhood deprivation may not only encompass physical health but may be more wide ranging and include mental health and quality of life.

Many participants reported physical health changes since the pandemic began. Strikingly, 57.72\% (740/1282) of participants reported being more sedentary, and $41.89 \%$ (537/1282) reported engaging in less physical activity. These results are in conjunction with $40.95 \%$ (525/1282) of participants reporting receiving less preventative or routine medical care. Lockdown measures have reduced physical activity opportunities, and these restrictions to limit the spread of COVID-19 infection may result in a less healthy populace [51]. Given the importance of early detection for many diseases, the impact of reduced preventative care combined with poorer engagement in health-promoting behaviors may be profound. As the risk of infection may remain high for some time, medical providers, administrators, and policymakers should continue to assess procedures to optimize care for all patients as well as identify safe avenues for increasing daily physical activity and reducing time spent sedentary [56].

\section{Limitations}

There are limitations of the findings reported in this study. A potential limitation of our survey study is self-selection bias, as participants may have joined the study because they were particularly interested in the topic. Although we used various recruitment methods, targeted efforts to improve representation, and placed a strong emphasis on anonymity and confidentiality, our UK sample was more likely to be White and from higher educational backgrounds, which is not representative of the UK population and so limits the generalizability of our findings to non-White and lower-income communities. Efforts to engage and form partnerships have begun to increase the representativeness of our sample for future longitudinal analyses. Additionally, data from Mexico ATTACH currently include over 1200 baseline assessments, so diverse between-country analyses will be possible for future waves. However, for the current UK baseline assessment, cultural factors and behavioral strategies specific to the UK, such as strong public messaging to protect the NHS, may mean our results do not generalize outside the UK.

This study began recruiting after the first UK lockdown (March 2020), so we lack real-time data from before the COVID-19 pandemic and cannot know if symptomology has changed. Further, indicators of preexisting mental health disorders and chronic medical conditions were based on self-report rather than clinical diagnoses. Given the unprecedented nature of the pandemic, we prioritized rapid deployment and data collection and so did not pilot test poll questions. However, many of the questions mirror those of other newly developed studies $[57,58]$. The fast changes related to the pandemic meant that we could not consider all possible predictors before study initiation, so there are no measures related to quarantine status, fear of COVID-19, duration of exposure to COVID-19-related information, and infection risk perception. Although $87 \%$ of the UK population has access to a smartphone, just $53 \%$ of those aged 65 or older have internet access via smartphone ownership [59]. Access to digital devices and the internet are also limited 
among other marginalized communities. Therefore, those who are digitally excluded are likely to be underrepresented in our sample.

\section{Strengths}

Strengths of our study include the mix of cross-sectional and longitudinal data collection methodology with the ability to assess daily attitudes and behaviors during the rapidly changing COVID-19 pandemic. Through the use of smartphone technology and mHealth, we can capture real-time responses and bridge physical distance. Participants completed most measures with little missing data, indicating that items were not burdensome. Finally, although our UK sample needs to increase representation related to ethnic and racialized identities, our Mexican sample includes a cross-section of communities. Through targeted recruitment, the United States sample includes an overrepresentation of participants who identified as Black or African American.

\section{Implications}

Smartphone apps are increasingly recognized as potentially powerful tools for mHealth studies and interventions [60,61]. They have been utilized successfully in adult and pediatric chronic illness populations [62-65] and in ecological momentary assessment studies and interventions [66,67]. Data from the UK ATTACH study demonstrate that people are also prepared to answer daily questions and provide mental health data in a longitudinal study using smartphone technology. Optimizing digital approaches and integrating them into the public health response is possible while considering logistical and technological barriers. However, currently, there is limited evidence that mHealth apps and interventions are cost-effective or cost-saving $[68,69]$. This engagement increases the feasibility of undertaking potentially sensitive longitudinal research and reduces retrospective judgments that tend to be affected by recall bias [67]. Because of this engagement, moving forward, the Mexico ATTACH study will use the Telegram messaging system to collect daily poll data, as they are widely accessible with an encrypted point-to-point connection. As we move forward, it will be necessary to include participants' input early in the research process to engender long- and short-term engagement [70].

\section{Conclusions}

Our data indicate that those with mental health disorders and chronic medical conditions are experiencing increased anxiety and depressive symptoms. Socioeconomic deprivation also appears to be a considerable risk factor for poor mental health. Although these challenges are not new, they could become more deep-rooted and challenging to tackle in this new COVID-19 era and beyond. Along with a renewed focus on mental health, investment to increase access to preventative medical care and messaging to encourage health-promoting behaviors, including physical activity, will be critical.

\section{Acknowledgments}

The authors want to thank all of the community stakeholders (ie, Crescent Kids) and organizations (ie, McPin Foundation), research recruitment sites (ie, Join Dementia Research, Call for Participants, Psychology on the Net), charity organizations (ie, Crohn's and Colitis UK, Pancreatic Cancer UK, Autistica, Sickle Cell Society, Parkinson's UK, Pancreatic Cancer UK), and the Avon \& Wiltshire Mental Health Partnership NHS Trust. AH was affiliated with the Developmental Neurosciences, Institute of Child Health, University College London at the time of the research. She is currently a Lecturer in the Division of Psychology and Mental Health at the University of Manchester.

\section{Authors' Contributions}

AH, HS, JM, MK, AS, CS, MP, NC-F, AR-A, MM, SW, MK, FK, and LC contributed to the conception and design of the study. AH, HS, JM, MK, AS, CS, MP, NC-F, AR-A, AB, AN, SG, MM, SW, MK, FK, and LC contributed to the organization of the conduct of the study. AH, CS, MP, NC-F, AR-A, AB, AN, and SG carried out the study (including data acquisition). AH and AS analyzed the data. AH drafted the initial output. All authors contributed to the interpretation of data. All authors have read and approved the final version of the manuscript.

\section{Conflicts of Interest}

The CCTST at the University of Cincinnati is funded by the National Institutes of Health (NIH) Clinical and Translational Science Award (CTSA) program, grant 2UL1TR001425-05A1. The CTSA program is led by the NIH's National Center for Advancing Translational Sciences (NCATS). The content of this manuscript is solely the responsibility of the CCTST and does not necessarily represent the official views of the NIH.

\section{Multimedia Appendix 1}

Complete list of daily poll questions and the assessment schedule.

[DOCX File , 28 KB-Multimedia Appendix 1]

\section{Multimedia Appendix 2}

Validated measures and assessment schedule in the ATTACH Study. [DOCX File, 17 KB-Multimedia Appendix 2] 


\section{Multimedia Appendix 3}

Non-validated measures and assessment schedule in the ATTACH Study.

[DOCX File, 15 KB-Multimedia Appendix 3]

\section{Multimedia Appendix 4}

Measures used in the ATTACH study.

[DOCX File, 1442 KB-Multimedia Appendix 4]

\section{Multimedia Appendix 5}

Recruitment strategies and example Facebook advertisement used in the ATTACH study.

[DOCX File, 835 KB-Multimedia Appendix 5]

\section{Multimedia Appendix 6}

Mental health disorders and medical conditions reported in the ATTACH study.

[DOCX File, 16 KB-Multimedia Appendix 6]

\section{Multimedia Appendix 7}

Participant characteristics at baseline in the UK ATTACH Study from June 26 to October 31, 2020.

[DOCX File, $20 \mathrm{~KB}-$ Multimedia Appendix 7]

\section{Multimedia Appendix 8}

Participant clinical classifications and severity on self-reported outcomes at baseline in the UK ATTACH study from June 26 to October 31, 2020.

[DOCX File, $15 \mathrm{~KB}-$ Multimedia Appendix 8]

\section{Multimedia Appendix 9}

Participant characteristics at baseline in the USA ATTACH Study from June 26 to October 31, 2020.

[DOCX File, 18 KB-Multimedia Appendix 9]

\section{Multimedia Appendix 10}

Participant characteristics at baseline in the Mexico ATTACH Study from October 6 to October 31, 2020.

[DOCX File, 18 KB-Multimedia Appendix 10]

\section{References}

1. World Health Organization. Coronavirus disease 2019 (COVID-19) Situation Report. Geneva, Switzerland: World Health Organization; 2020.

2. Prü $\beta$ BM. Current state of the first COVID-19 vaccines. Vaccines (Basel) 2021 Jan 08;9(1):30 [FREE Full text] [doi: 10.3390/vaccines9010030] [Medline: $\underline{33429880]}$

3. Mahase E. Vaccinating the UK: how the COVID vaccine was approved, and other questions answered. BMJ 2020 Dec 09;371:m4759. [doi: 10.1136/bmj.m4759] [Medline: 33298577]

4. Cofepris aprueba uso en emergencias de vacuna Pfizer contra COVID-19. URL: https://www.gob.mx/salud/prensa/ 249-cofepris-aprueba-uso-en-emergencias-de-vacuna-pfizer-contra-covid-19 [accessed 2021-08-30]

5. Lewnard JA, Lo NC. Scientific and ethical basis for social-distancing interventions against COVID-19. The Lancet Infectious Diseases 2020 Jun;20(6):631-633. [doi: 10.1016/s1473-3099(20)30190-0]

6. Jiang F, Deng L, Zhang L, Cai Y, Cheung CW, Xia Z. Review of the clinical characteristics of Coronavirus Disease 2019 (COVID-19). J Gen Intern Med 2020 May;35(5):1545-1549 [FREE Full text] [doi: 10.1007/s11606-020-05762-w] [Medline: 32133578]

7. Everett JAC, Colombatto C, Chituc V, Brady WJ, Crockett M. The effectiveness of moral messages on public health behavioral intentions during the COVID-19 pandemic. PsyArXiv Preprints . [doi: 10.31234/osf.io/9yqs8]

8. Galea S, Merchant RM, Lurie N. The mental health consequences of COVID-19 and physical distancing: the need for prevention and early intervention. JAMA Intern Med 2020 Jun 01;180(6):817-818. [doi: 10.1001/jamainternmed.2020.1562] [Medline: 32275292] 
9. Bueno-Notivol J, Gracia-García P, Olaya B, Lasheras I, López-Antón R, Santabárbara J. Prevalence of depression during the COVID-19 outbreak: A meta-analysis of community-based studies. Int J Clin Health Psychol 2021;21(1):100196 [FREE Full text] [doi: 10.1016/j.ijchp.2020.07.007] [Medline: $\underline{\text { 32904715] }}$

10. Cluver L, Lachman JM, Sherr L, Wessels I, Krug E, Rakotomalala S, et al. Parenting in a time of COVID-19. The Lancet 2020 Apr;395(10231):e64. [doi: 10.1016/s0140-6736(20)30736-4]

11. Bonanno GA, Brewin CR, Kaniasty K, Greca AML. Weighing the costs of disaster: consequences, risks, and resilience in individuals, families, and communities. Psychol Sci Public Interest 2010 Jan 01;11(1):1-49. [doi: 10.1177/1529100610387086] [Medline: 26168411]

12. Cobham VE, McDermott B, Haslam D, Sanders MR. The role of parents, parenting and the family environment in children's post-disaster mental health. Curr Psychiatry Rep 2016 Jun 16;18(6):53. [doi: 10.1007/s11920-016-0691-4] [Medline: $\underline{27086314}$ ]

13. Masten AS, Motti-Stefanidi F. Multisystem resilience for children and youth in disaster: reflections in the context of COVID-19. Advers Resil Sci 2020 Jun 25;1(2):1-12 [FREE Full text] [doi: 10.1007/s42844-020-00010-w] [Medline: $\underline{32838305]}$

14. Shultz JM, Baingana F, Neria Y. The 2014 Ebola outbreak and mental health: current status and recommended response. JAMA 2015 Feb 10;313(6):567-568. [doi: 10.1001/jama.2014.17934] [Medline: 25532102]

15. Mak IWC, Chu CM, Pan PC, Yiu MGC, Chan VL. Long-term psychiatric morbidities among SARS survivors. Gen Hosp Psychiatry 2009 Jul;31(4):318-326 [FREE Full text] [doi: 10.1016/j.genhosppsych.2009.03.001] [Medline: 19555791]

16. Najam S. Multidisciplinary research priorities for the COVID-19 pandemic. The Lancet Psychiatry 2020 Jul;7(7):e34. [doi: 10.1016/s2215-0366(20)30238-8]

17. Paton A, Fooks G, Maestri G, Lowe P. Submission of evidence on the disproportionate impact of COVID-19, the UK government response, on ethnic minorities in the UK. 2020. URL: http://publications.aston.ac.uk/id/eprint/41460/ [accessed 2020-11-11]

18. Fenton K, Pawson E, de Souza-Thomas L. Beyond the data: Understanding the impact of COVID-19 on BAME groups. Public Health England. 2020. URL: https://assets.publishing.service.gov.uk/government/uploads/system/uploads/ attachment data/file/892376/COVID stakeholder engagement synthesis beyond the data.pdf [accessed 2020-11-11]

19. Lemstra M, Neudorf C, D'Arcy C, Kunst A, Warren LM, Bennett NR. A Systematic Review of Depressed Mood and Anxiety by SES in Youth Aged 10-15 Years. Can J Public Health 2008 Mar 1;99(2):125-129. [doi: 10.1007/bf03405459]

20. Lorant V, Deliège D, Eaton W, Robert A, Philippot P, Ansseau M. Socioeconomic inequalities in depression: a meta-analysis. Am J Epidemiol 2003 Jan 15;157(2):98-112. [doi: 10.1093/aje/kwf182] [Medline: 12522017]

21. Dalglish SL. COVID-19 gives the lie to global health expertise. The Lancet 2020 Apr;395(10231):1189. [doi: 10.1016/s0140-6736(20)30739-x]

22. Dahal S, Banda JM, Bento AI, Mizumoto K, Chowell G. Characterizing all-cause excess mortality patterns during COVID-19 pandemic in Mexico. BMC Infect Dis 2021 May 07;21(1):432 [FREE Full text] [doi: 10.1186/s12879-021-06122-7] [Medline: $\underline{33962563]}$

23. Michie S, West R, Amlôt R. Behavioural strategies for reducing covid-19 transmission in the general population. The Communication Initiative Network. 2020. URL: https://www.comminit.com/content/ behavioural-strategies-reducing-covid-19-transmission-general-population [accessed 2020-12-11]

24. Acuña-Zegarra MA, Santana-Cibrian M, Velasco-Hernandez JX. Modeling behavioral change and COVID-19 containment in Mexico: A trade-off between lockdown and compliance. Math Biosci 2020 Jul;325:108370 [FREE Full text] [doi: 10.1016/j.mbs.2020.108370] [Medline: 32387384]

25. Hutchins HJ, Wolff B, Leeb R, Ko JY, Odom E, Willey J, et al. COVID-19 Mitigation Behaviors by Age Group - United States, April-June 2020. MMWR Morb Mortal Wkly Rep 2020 Oct 30;69(43):1584-1590 [FREE Full text] [doi: 10.15585/mmwr.mm6943e4] [Medline: 33119562]

26. Hood AM, Noser A, Corral-Frías NS, Murphy J, Kirkham F, Stotesbury H, et al. Attitudes About COVID-19 and Health (ATTACH) study. 2021. URL: https://osf.io/pdfb5/ [accessed 2021-02-19]

27. von Elm E, Altman DG, Egger M, Pocock SJ, Gøtzsche PC, Vandenbroucke JP, STROBE Initiative. The Strengthening the Reporting of Observational Studies in Epidemiology (STROBE) statement: guidelines for reporting observational studies. Ann Intern Med 2007 Oct 16;147(8):573-577 [FREE Full text] [doi: 10.7326/0003-4819-147-8-200710160-00010] [Medline: 17938396 ]

28. Eysenbach G. Improving the quality of Web surveys: the Checklist for Reporting Results of Internet E-Surveys (CHERRIES). J Med Internet Res 2004 Sep 29;6(3):e34 [FREE Full text] [doi: 10.2196/jmir.6.3.e34] [Medline: 15471760]

29. American Psychiatric Association. Diagnostic and Statistical Manual of Mental Disorders (5th edition). Washington, D.C: American Psychiatric Association; May 18, 2013.

30. Cella D, Riley W, Stone A, Rothrock N, Reeve B, Yount S, PROMIS Cooperative Group. The Patient-Reported Outcomes Measurement Information System (PROMIS) developed and tested its first wave of adult self-reported health outcome item banks: 2005-2008. J Clin Epidemiol 2010 Nov;63(11):1179-1194 [FREE Full text] [doi: 10.1016/j.jclinepi.2010.04.011] [Medline: 20685078] 
31. Martin A, Rief W, Klaiberg A, Braehler E. Validity of the Brief Patient Health Questionnaire Mood Scale (PHQ-9) in the general population. Gen Hosp Psychiatry 2006 Jan;28(1):71-77. [doi: 10.1016/j.genhosppsych.2005.07.003] [Medline: 16377369]

32. Russell DW. UCLA Loneliness Scale (Version 3): reliability, validity, and factor structure. J Pers Assess 1996 Feb;66(1):20-40. [doi: 10.1207/s15327752jpa6601 2] [Medline: $\underline{8576833]}$

33. Grasso DJ, Briggs-Gowan MJ, Carter AS, Goldstein BL, Ford JD. Profiling COVID-related experiences in the United States with the Epidemic-Pandemic Impacts Inventory: Linkages to psychosocial functioning. Brain Behav 2021 Aug 03;11(8):e02197 [FREE Full text] [doi: 10.1002/brb3.2197] [Medline: 34216110]

34. Crone J. Office for National Statistics Postcode Directory (ONSPD) Open February 2011 edition. Edinburgh Data Share. 2011. URL: https://datashare.ed.ac.uk/handle/10283/2465 [accessed 2021-03-23]

35. Ministry of Housing. The English Indices of Deprivation 2019 (IoD2019). 2019. URL: https://www.gov.uk/government/ statistics/english-indices-of-deprivation-2019 [accessed 2021-01-24]

36. Welsh Index of Multiple Deprivation (full Index update with ranks): 2019. 2019. URL: https://gov.wales/ welsh-index-multiple-deprivation-full-index-update-ranks-2019 [accessed 2021-01-24]

37. Scottish Government. Scottish Index of Multiple Deprivation 2020. 2019. URL: https://www.gov.scot/collections/ scottish-index-of-multiple-deprivation-2020/ [accessed 2021-01-24]

38. Northern Ireland Statistics and Research Agency. Northern Ireland Multiple Deprivation Measure 2017 (NIMDM2017). 2017. URL: https://www.nisra.gov.uk/statistics/deprivation/northern-ireland-multiple-deprivation-measure-2017-nimdm2017 [accessed 2021-01-24]

39. Office for National Statistics. Key Statistics - Census. 2011. URL: https://www.ons.gov.uk [accessed 2021-01-24]

40. Scottish Census. Standard Outputs: Population Density. 2011. URL: https://www.scotlandscensus.gov.uk/ods-web/ standard-outputs.html?year=2011\&table=QS102SC\&tableDescription=Population [accessed 2021-01-24]

41. Northern Ireland Statistics and Research Agency, "Population Statistics,". 2011. URL: https://www.ninis2.nisra.gov.uk/ public/Theme.aspx?themeNumber=74\&themeName=Population [accessed 2021-02-20]

42. Harris PA, Taylor R, Thielke R, Payne J, Gonzalez N, Conde JG. Research electronic data capture (REDCap)--a metadata-driven methodology and workflow process for providing translational research informatics support. J Biomed Inform 2009 Apr;42(2):377-381 [FREE Full text] [doi: 10.1016/j.jbi.2008.08.010] [Medline: 18929686]

43. Obeid JS, McGraw CA, Minor BL, Conde JG, Pawluk R, Lin M, et al. Procurement of shared data instruments for Research Electronic Data Capture (REDCap). J Biomed Inform 2013 Apr;46(2):259-265 [FREE Full text] [doi:

10.1016/j.jbi.2012.10.006] [Medline: 23149159]

44. The R Foundation. Language and Environment for Statistical Computing. 2018. URL: https://www.R-project.org [accessed 2019-05-21]

45. SAS Institute. Base SAS 9.4 Procedures Guide, Seventh Edition. 2015. URL: https://documentation.sas.com/doc/en/ pgmsascdc/9.4_3.5/proc/titlepage.htm [accessed 2021-03-02]

46. HealthMeasures Scoring Service powered by Assessment Center. URL: https://www.assessmentcenter.net/ac scoringservice [accessed 2020-11-05]

47. Kroenke K, Spitzer RL, Williams JB, Löwe B. The Patient Health Questionnaire Somatic, Anxiety, and Depressive Symptom Scales: a systematic review. Gen Hosp Psychiatry 2010 Jul;32(4):345-359. [doi: 10.1016/j.genhosppsych.2010.03.006] [Medline: 20633738]

48. Penning MJ, Liu G, Chou PHB. Measuring Loneliness Among Middle-Aged and Older Adults: The UCLA and de Jong Gierveld Loneliness Scales. Soc Indic Res 2013 Oct 1;118(3):1147-1166. [doi: 10.1007/s11205-013-0461-1]

49. Jia R, Ayling K, Chalder T, Massey A, Broadbent E, Coupland C, et al. Mental health in the UK during the COVID-19 pandemic: cross-sectional analyses from a community cohort study. BMJ Open 2020 Sep 15;10(9):e040620 [FREE Full text] [doi: 10.1136/bmjopen-2020-040620] [Medline: 32933965]

50. Pierce M, Hope H, Ford T, Hatch S, Hotopf M, John A, et al. Mental health before and during the COVID-19 pandemic: a longitudinal probability sample survey of the UK population. The Lancet Psychiatry 2020 Oct;7(10):883-892. [doi: $10.1016 / \mathrm{s} 2215-0366(20) 30308-4]$

51. Daly M, Sutin AR, Robinson E. Longitudinal changes in mental health and the COVID-19 pandemic: evidence from the UK Household Longitudinal Study. Psychol. Med 2020 Nov 13:1-10. [doi: 10.1017/s0033291720004432]

52. Pieh C, Budimir S, Delgadillo J, Barkham M, Fontaine JRJ, Probst T. Mental Health During COVID-19 Lockdown in the United Kingdom. Psychosom Med 2020 Oct 2;83(4):328-337. [doi: 10.1097/psy.0000000000000871]

53. Petts R, Carlson D, Pepin J. A gendered pandemic: Childcare, homeschooling, and parents' employment during COVID - 19. Gender Work Organ 2021 Jan 13;28(S2):515-534. [doi: 10.1111/gwao.12614]

54. Chakrabarti S, Hamlet LC, Kaminsky J, Subramanian SV. Association of Human Mobility Restrictions and Race/Ethnicity-Based, Sex-Based, and Income-Based Factors With Inequities in Well-being During the COVID-19 Pandemic in the United States. JAMA Netw Open 2021 Apr 01;4(4):e217373 [FREE Full text] [doi: $\underline{10.1001 / j a m a n e t w o r k o p e n .2021 .7373]}$ [Medline: $\underline{33825836}$ ] 
55. Khawaja AP, Warwick AN, Hysi PG, Kastner A, Dick A, Khaw PT, et al. Associations with covid-19 hospitalisation amongst 406,793 adults: the UK Biobank prospective cohort study. MedRxiv 2020 May 11 [FREE Full text] [doi: 10.1101/2020.05.06.20092957]

56. Serlachius A, Badawy SM, Thabrew H. Psychosocial Challenges and Opportunities for Youth With Chronic Health Conditions During the COVID-19 Pandemic. JMIR Pediatr Parent 2020 Oct 12;3(2):e23057 [FREE Full text] [doi: 10.2196/23057] [Medline: 33001834]

57. Hagger MS, Smith SR, Keech JJ, Moyers SA, Hamilton K. Predicting Social Distancing Intention and Behavior During the COVID-19 Pandemic: An Integrated Social Cognition Model. Ann Behav Med 2020 Oct 01;54(10):713-727 [FREE

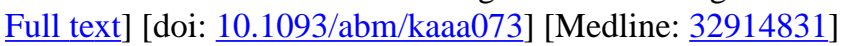

58. Armour C, McGlinchey E, Butter S, McAloney-Kocaman K, McPherson KE. The COVID-19 Psychological Wellbeing Study: Understanding the Longitudinal Psychosocial Impact of the COVID-19 Pandemic in the UK; a Methodological Overview Paper. J Psychopathol Behav Assess 2020 Nov 04;43(1):1-17 [FREE Full text] [doi: 10.1007/s10862-020-09841-4] [Medline: $\underline{33169046]}$

59. Number of mobile phone users worldwide from 2015 to 2020 (in billions). 2020. URL: https://www.statista.com/statistics/ 274774/forecast-of-mobile-phone-users-worldwide/ [accessed 2021-01-05]

60. Zapata BC, Fernández-Alemán JL, Idri A, Toval A. Empirical studies on usability of mHealth apps: a systematic literature review. J Med Syst 2015 Feb 20;39(2):1. [doi: 10.1007/s10916-014-0182-2] [Medline: 25600193]

61. Luxton DD, McCann RA, Bush NE, Mishkind MC, Reger GM. mHealth for mental health: Integrating smartphone technology in behavioral healthcare. Professional Psychology: Research and Practice 2011 Dec;42(6):505-512. [doi: 10.1037/a0024485]

62. Farzandipour M, Nabovati E, Sharif R, Arani M, Anvari S. Patient Self-Management of Asthma Using Mobile Health Applications: A Systematic Review of the Functionalities and Effects. Appl Clin Inform 2017 Dec 14;08(04):1068-1081. [doi: 10.4338/aci-2017-07-r-0116]

63. Badawy SM, Cronin RM, Hankins J, Crosby L, DeBaun M, Thompson AA, et al. Patient-Centered eHealth Interventions for Children, Adolescents, and Adults With Sickle Cell Disease: Systematic Review. J Med Internet Res 2018 Jul 19;20(7):e10940 [FREE Full text] [doi: 10.2196/10940] [Medline: 30026178]

64. Hood AM, Nwankwo C, Walton A, McTate E, Joffe N, Quinn CT, et al. Mobile health use predicts self-efficacy and self-management in adolescents with sickle cell disease. Transl Behav Med 2021 May 05:57-58. [doi: 10.1093/tbm/ibab041] [Medline: 33949674]

65. Garabedian LF, Ross-Degnan D, Wharam JF. Mobile Phone and Smartphone Technologies for Diabetes Care and Self-Management. Curr Diab Rep 2015 Dec 12;15(12):109 [FREE Full text] [doi: 10.1007/s11892-015-0680-8] [Medline: 26458380]

66. Runyan JD, Steenbergh TA, Bainbridge C, Daugherty DA, Oke L, Fry BN. A smartphone ecological momentary assessment/intervention "app" for collecting real-time data and promoting self-awareness. PLoS One 2013 Aug 14;8(8):e71325 [FREE Full text] [doi: 10.1371/journal.pone.0071325] [Medline: 23977016]

67. Runyan JD, Steinke EG. Virtues, ecological momentary assessment/intervention and smartphone technology. Front Psychol 2015 May 06;6:481 [FREE Full text] [doi: 10.3389/fpsyg.2015.00481] [Medline: 25999869]

68. Iribarren SJ, Cato K, Falzon L, Stone PW. What is the economic evidence for mHealth? A systematic review of economic evaluations of mHealth solutions. PLoS One 2017 Feb 2;12(2):e0170581 [FREE Full text] [doi:

10.1371/journal.pone.0170581] [Medline: 28152012]

69. Badawy SM, Kuhns LM. Economic Evaluation of Text-Messaging and Smartphone-Based Interventions to Improve Medication Adherence in Adolescents with Chronic Health Conditions: A Systematic Review. JMIR Mhealth Uhealth 2016 Oct 25;4(4):e121 [FREE Full text] [doi: 10.2196/mhealth.6425] [Medline: 27780795]

70. Perski O, Blandford A, West R, Michie S. Conceptualising engagement with digital behaviour change interventions: a systematic review using principles from critical interpretive synthesis. Transl Behav Med 2017 Jun;7(2):254-267 [FREE Full text] [doi: 10.1007/s13142-016-0453-1] [Medline: 27966189]

\section{Abbreviations}

AMO: Air My Opinion

ATTACH: Attitudes About COVID-19 and Health

GDPR: General Data Protection Regulation

NHS: National Health Service

PROMIS: Patient-Reported Outcomes Measurement Information System

PHQ-9: 9-item Patient Health Questionnaire

REDCap: Research Electronic Data Capture

STROBE: STrengthening the Reporting of OBservational studies in Epidemiology

UCL: University College London

UCLA-10: 10-item University of California Los Angeles Loneliness Scale

WHO: World Health Organization 
Edited by J Torous; submitted 27.04.21; peer-reviewed by S Nochaiwong, J Parsons, S Badawy, MD, MS, A Johnson; comments to author 22.05.21; revised version received 12.07.21; accepted 28.07.21; published 07.10.21

Please cite as:

Hood AM, Stotesbury H, Murphy J, Kölbel M, Slee A, Springall C, Paradis M, Corral-Frías NS, Reyes-Aguilar A, Cuellar Barboza AB, Noser AE, Gomes S, Mitchell M, Watkins SM, Butsch Kovacic M, Kirkham FJ, Crosby LE

Attitudes About COVID-19 and Health (ATTACH): Online Survey and Mixed Methods Study

JMIR Ment Health 2021;8(10):e29963

URL: https://mental.jmir.org/2021/10/e29963

doi: $10.2196 / 29963$

PMID: 34357877

(C)Anna M Hood, Hanne Stotesbury, Jennifer Murphy, Melanie Kölbel, April Slee, Charlie Springall, Matthew Paradis, Nadia Saraí Corral-Frías, Azalea Reyes-Aguilar, Alfredo B Cuellar Barboza, Amy E Noser, Stacey Gomes, Monica Mitchell, Sharon M Watkins, Melinda Butsch Kovacic, Fenella J Kirkham, Lori E Crosby. Originally published in JMIR Mental Health (https://mental.jmir.org), 07.10.2021. This is an open-access article distributed under the terms of the Creative Commons Attribution License (https://creativecommons.org/licenses/by/4.0/), which permits unrestricted use, distribution, and reproduction in any medium, provided the original work, first published in JMIR Mental Health, is properly cited. The complete bibliographic information, a link to the original publication on https://mental.jmir.org/, as well as this copyright and license information must be included. 